\title{
Comparison of Convective Boundary Layer Characteristics from Aircraft and Wind Lidar Observations
}

\author{
Bianca Adler, Olga Kiseleva, Norbert Kalthoff, And Andreas Wieser \\ Karlsruhe Institute of Technology, Karlsruhe, Germany
}

(Manuscript received 16 July 2018, in final form 3 April 2019)

\begin{abstract}
During the Convective Storm Initiation Project experiment, which was conducted in summer 2005 in southern England, vertical velocity in the convective boundary layer (CBL) was measured simultaneously with a research aircraft and a wind lidar. The aircraft performed horizontal flight legs approximately parallel to the prevailing wind direction and centered over the lidar. This measurement setup allows for the comparing of CBL characteristics (CBL depth $z_{i}$, integral length scale $l_{w}$, spectral peak wavelength $\lambda_{m}$, and vertical velocity variance $\sigma_{w}^{2}$ ) from temporal (lidar) and spatial (aircraft) measurements. For this, the lidar time series are transferred into space using the mean wind. While the statistics of the aircraft data are all based on the $34-\mathrm{km}$ flight legs, the averaging interval for the lidar is either $1 \mathrm{~h}$ or a longer period that corresponds to the $34-\mathrm{km} \mathrm{leg}$. Although the $l_{w}$ and $\lambda_{m}$ values from aircraft and lidar measurements are in the same range (100200 and 500-2000 m) and agree well on the average, the correlation for individual legs is very low $\left(R^{2}<0.17\right)$. One possible explanation is the large uncertainty that arises from the transfer of the lidar time series to space. For $\sigma_{w}^{2}$, the agreement between aircraft and lidar is better for individual legs $\left(R^{2} \geq 0.63\right)$, but the mean absolute difference in $\sigma_{w}^{2}$ is about 2.5 times as large as the statistical error. We examine the nonstationarity and heterogeneity for the lidar and aircraft samples and can exclude these as the major sources for the large differences between lidar and aircraft data.
\end{abstract}

\section{Introduction}

The exchange between Earth's surface and the atmosphere in the convective boundary layer (CBL) is dominated by convection (surface-based buoyancy driven turbulent mixing) over horizontally homogeneous flat terrain under fair weather conditions during daytime. To characterize the CBL often used parameters are the CBL depth $z_{i}$, the vertical velocity variance $\sigma_{w}^{2}$ (as a measure of turbulence), the integral length scale $l_{w}$ (as the length scale over which turbulence remains correlated), and the spectral peak wavelength $\lambda_{m}$ (as the size of the eddies with the most energy). Reliable measurement of these parameters is crucial for the understanding of the CBL structure and evolution.

Variance profiles can be derived from aircraft observations using spatial averages (e.g., Lenschow and Stephens 1980; Lenschow 1986; Young 1988; Grunwald et al. 1998) and from tower or wind lidar measurements using temporal averages (e.g., Neff 1990; Grund et al. 2001; Emeis 2011; Banta et al. 2013). Both spatial and

Corresponding author: Bianca Adler, bianca.adler@kit.edu temporal averages are associated with errors due to deviations from the ensemble average, insufficient sample lengths and instationary and/or inhomogeneous conditions (e.g., Stull 1988; Mahrt 1998). According to Lenschow and Stankov (1986), variances based on aircraft observations can be estimated within approximately $10 \%$ accuracy when the flight legs are long enough. However, aircraft do not allow continuous observations, and measurements at various subsequent levels could be in conflict with the demand for stationary conditions, especially during phases of rapid CBL evolution. In addition, as flight hours are still quite expensive, the use of aircraft is mostly limited to scientific investigations. A comprehensive assessment of the advantages and disadvantages of aircraft measurements for CBL studies is overviewed by Lenschow (1986) and Mahrt (1998).

Since the proliferation of wind lidars was fostered in recent years by commercial application-for example, wind energy potential assessment-they became more and more affordable for scientific research institutes, and the number of publications utilizing wind lidar data more than doubled in the period 2009-18 compared to 
1998-2008 (Web of Science 2018a,b). Different scan strategies were developed and tested in order to derive turbulence quantities. For example, Pearson et al. (2010), Barlow et al. (2011), Bonin et al. (2015), and Tonttila et al. (2015) used vertical pointing lidars to derive profiles of vertical velocity spectra and $\sigma_{w}^{2}$. Newman et al. (2016a,b) applied and validated multilidar measurements and different scanning strategies to determine turbulent quantities. CBL profiles of variances and covariances appear to be consistent with expectations, but independent comparisons are still needed (Banta et al. 2013), because up until now, verifications were mainly based on tower data; that is, they were available for the lower part of the CBL only (e.g., Mann et al. 2009; Fuertes et al. 2014; Brugger et al. 2016; Bonin et al. 2017). The simultaneous operation of lidar and aircraft facilitates comparative measurements and allows for the assessment of the comparability of data from both platforms.

Various possible reasons for differences of CBL characteristics obtained from both observation platforms exist and are reported in literature:

(i) Vertical velocity measurements by lidar may not allow for resolving the whole turbulence spectrum. Lidar measurements are not point measurements, but rather an average over a sample volume depending on pulse width, range-gate length, and time resolution, which hinders the resolution of the shortwave end of the turbulence spectrum (e.g., Frehlich 1997). Comparisons to tower measurements show (Brugger et al. 2016) that this beam averaging effect can be partly reduced when applying appropriate correction methods (Frehlich and Cornman 2002).

(ii) To compare temporal to spatial averages, the time series has to be transferred to space using the translation speed of the convective cells. As this translation speed is not exactly known, a mean horizontal wind speed is often used to transfer the samples from time to space, hereafter named transfer wind speed. This is a critical assumption (e.g., Powell and Elderkin 1974) and might result in considerable uncertainty of the CBL characteristics derived from temporal averages based on tower or lidar data.

(iii) A systematic error arises from the deviation of spatial and temporal averages from the ensemble average and a random error or sampling error takes into account that the sample length is not unlimited and that "random" sample lengths may be different. Lenschow et al. (1994) formulate expressions to estimate the systematic and random errors for $\sigma_{w}^{2}$ that depend on $\sigma_{w}^{2}, l_{w}$, and the sample length $S$. (iv) Even when the systematic and random errors are small, nonstationary (for lidar measurements) or heterogeneous (for aircraft measurements) conditions during the averaging intervals may inhibit meaningful estimates of turbulence characteristics. Mahrt (1998) presents a measure of nonstationarity (heterogeneity) that is based on the fact that during stationary conditions, the variability between record means is predicted by the standard error of the record mean due to random variability.

During the Convective Storm Initiation Project (CSIP; Browning et al. 2007), conducted in 2005 in southern England, both a research aircraft and a wind lidar were operated simultaneously and measured vertical velocity in the CBL. From this data, $z_{i}, \sigma_{w}^{2}, l_{w}$, and $\lambda_{m}$ were calculated as estimates of the CBL characteristics. The aim of this investigation is (i) to compare aircraft- and wind lidar-derived values of $\sigma_{w}^{2}, l_{w}$, and $\lambda_{m}$ (section 4) and (ii) to discuss the abovementioned possible reasons for differences (transfer wind speed, nonstationarity/spatial heterogeneity, and statistical error) (section 5).

\section{The measurement campaign}

\section{a. Measurement site and observation periods}

The CSIP campaign was performed from June to August 2005 in the surroundings of Chilbolton in southern England (Figs. 1a,b). The investigation area is characterized by an intermediate level of orography, the vegetation cover is rather uniform, and only some smaller urban areas exist (the largest urban areas have diameters of approximately $15 \mathrm{~km}$ ) (Browning et al. 2007; Marsham et al. 2007). During the campaign, a wind lidar was located at the site of Chilbolton Observatory, United Kingdom, at $51^{\circ} 08.42^{\prime} \mathrm{N}, 1^{\circ} 26.23^{\prime} \mathrm{E}, 80 \mathrm{~m}$ above mean sea level (MSL) and approximately $45 \mathrm{~km}$ off of the coastline (Fig. 1b). The system was operated continuously from 19 June to 28 August 2005. Next to the wind lidar, an energy balance station (Kalthoff et al. 2006) was installed providing meteorological nearsurface conditions and energy balance components used for scaling purposes. During intensive operation period (IOP) days, flights were performed with the Dornier 128 research aircraft D-IBUF (Do 128), operated by the Institute of Flight Guidance of Technische Universität Braunschweig, Germany, whose base was at Thruxton airport (Fig. 1b). Radiosondes providing temperature, humidity, and horizontal wind profiles were launched regularly in 1- or 2-h intervals during IOP days. 

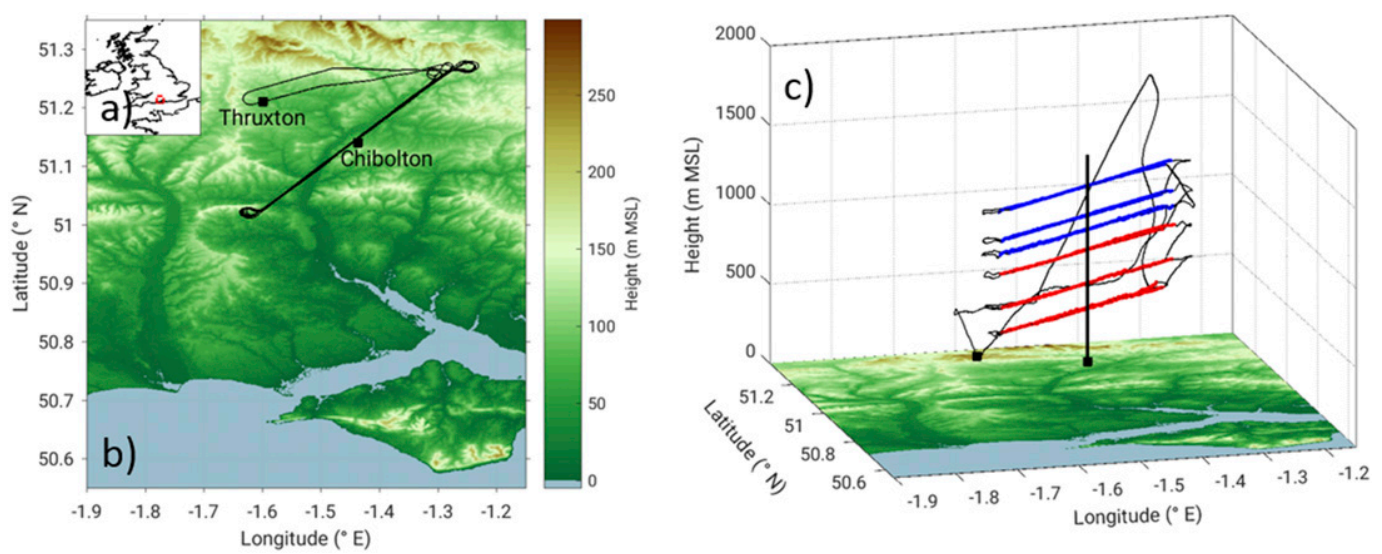

FIG. 1. (a) Location of the CSIP investigation area (red box) in southern England. (b) Topography in the CSIP investigation area in the surroundings of Chilbolton and a two-dimensional view of the flight legs of the Dornier 128 research aircraft. The flight legs cover a distance of $34 \mathrm{~km}$ (excluding turns) and are centered on the lidar site at Chilbolton Observatory. (c) Three-dimensional display of the flight pattern (thin solid line). After takeoff at Thruxton, a vertical profile was flown, and then the aircraft flew along horizontal legs at six different heights in (red) and above (blue) the CBL. The legs were oriented from northeast to southwest. The laser beam during the vertical stare mode of the lidar at Chilbolton is indicated as a thick solid line.

While the focus of the CSIP project was on the evolution of moist convection, some IOP days were conducted during high pressure conditions with southwesterly or northeasterly winds, during which a mostly cloud-free CBL developed. Three IOPs performed under such conditions are investigated in this study. During these IOPs, five flights were conducted in total-three in the morning, and two in the early afternoon (Table 1). Datasets 1 and 2 were obtained from flights on 22 June, from 0917 to 1126 UTC (flight A) and 1232 to 1500 UTC (flight B); datasets 3 and 4 were obtained on 27 June, from 1009 to 1219 UTC (flight C) and 1344 to 1613 UTC (flight D); and dataset 5 was obtained on 14 July, from 1032 to 1231 UTC (flight E). We only use data from flight levels within the CBL. Table 1 provides an overview of dates and time periods of the flights, the heights of the aircraft legs at the passage over the lidar site, and the heights of the closest wind lidar range gate, and Fig. 2 summarizes the main CBL characteristics during the flights.

\section{b. Aircraft instrumentation and flight pattern}

The Do 128 is especially well suited for turbulence measurements within the CBL because of its low cruising speed of $65 \mathrm{~m} \mathrm{~s}^{-1}$ together with fast and accurate turbulence sensors and high-precision navigation systems (Corsmeier et al. 2001; Hasel et al. 2005). The wind velocity is measured with a Rosemount 5-hole probe mounted at the tip of a 3.7-m-long nose boom outside the area influenced by the aircraft. The probe is connected to Setra pressure sensors mounted inside the boom, approximately $0.2 \mathrm{~m}$ behind the tip. Temperature is measured with a Rosemount PT100 mounted on top of the boom and by an open platinum wire. Humidity

TABLE 1. Dates and time periods of the Do 128 flights. The heights of the utilized flight legs in the CBL $\left(H_{\text {Do }}\right)$ and the heights of the closest wind lidar range gate (center) $\left(H_{\mathrm{Li}}\right)$ are given in $\mathrm{m}$ above ground level (AGL). $H_{\mathrm{Do}}$ is determined at the overpass of the aircraft at the lidar site. Legs indicated with "_-"are either not in the CBL or not used in the analysis because of missing lidar data in the respective level. B2 and B5 are legs that are shown in more detail in the analysis.

\begin{tabular}{|c|c|c|c|c|c|c|}
\hline \multicolumn{2}{|l|}{ Flight } & \multirow{2}{*}{$\frac{\text { Flight } A}{22 \text { Jun } 2005}$} & \multirow{2}{*}{$\begin{array}{c}\text { Flight B } \\
\text { 22 Jun } 2005\end{array}$} & \multirow{2}{*}{$\frac{\text { Flight C }}{27 \text { Jun } 2005}$} & \multirow{2}{*}{$\frac{\text { Flight D }}{27 \text { Jun } 2005}$} & \multirow{2}{*}{$\frac{\text { Flight E }}{14 \text { Jul } 2005}$} \\
\hline Date & & & & & & \\
\hline Time (UTC) & Leg & 0917-1126 & $1232-1500$ & 1009-1219 & $1344-1613$ & $1032-1231$ \\
\hline \multirow[t]{6}{*}{$H_{\mathrm{Do}} \mid H_{\mathrm{Li}}(\mathrm{m} \mathrm{AGL})$} & 1 & - & - & - & - & - \\
\hline & 2 & $483 \mid 438$ & $477 \mid 438(\mathrm{~B} 2)$ & $426 \mid 435$ & $472 \mid 468$ & $455 \mid 435$ \\
\hline & 3 & - & $693 \mid 693$ & $522 \mid 534$ & $594 \mid 600$ & $668 \mid 682$ \\
\hline & 4 & - & $910 \mid 947$ & - & $721 \mid 715$ & $762 \mid 781$ \\
\hline & 5 & - & $1102 \mid 1151$ (B5) & - & $840 \mid 830$ & $973 \mid 979$ \\
\hline & 6 & - & - & - & $959 \mid 962$ & - \\
\hline
\end{tabular}



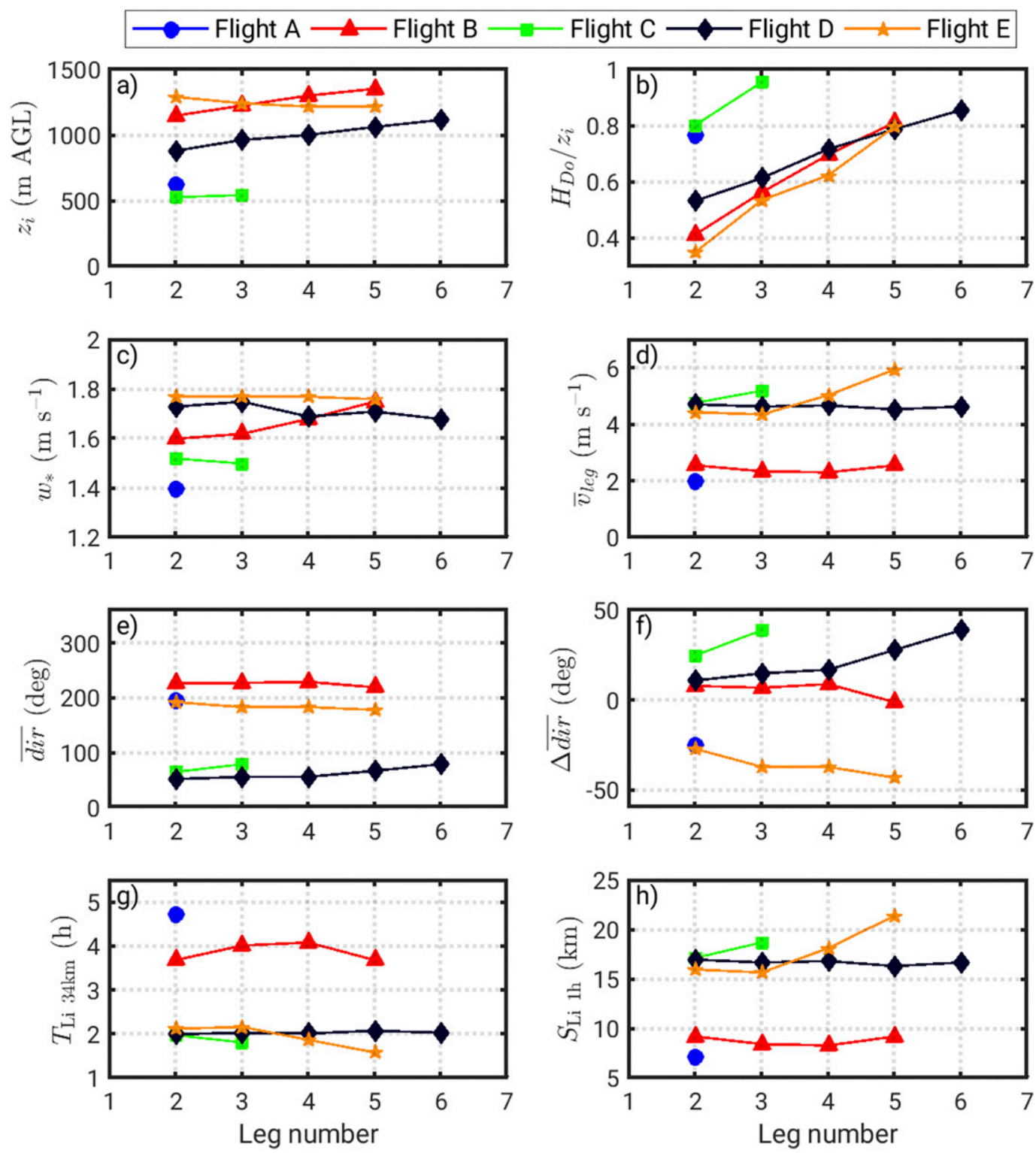

FIG. 2. Overview of different characteristics during the legs flown in the CBL and used in this study for flights AE (see Table 1): (a) mean CBL depth $z_{i}$ during the individual flight legs determined from wind lidar data (gradient method), (b) normalized height of the flight legs with respect to $z_{i} H_{\mathrm{Do}} / z_{i}$, (c) convective velocity scale $w_{*}$, (d) mean wind speed along the legs $\bar{v}_{\text {leg }}$, (e) mean wind direction along the legs $\overline{\operatorname{dir}}$, (f) difference in the angle between the wind direction averaged over the flight leg and the orientation of the respective flight leg $\Delta \overline{\mathrm{dir}},(\mathrm{g})$ lidar averaging interval $T_{\mathrm{Li} 34 \mathrm{~km}}$ corresponding to $34 \mathrm{~km}$, and (h) lidar averaging interval $S_{\mathrm{Li} 1 \mathrm{~h}}$ corresponding to $1 \mathrm{~h}$.

sensors (Lyman- $\alpha$ hygrometer, dewpoint mirror, and Humicap) are also mounted inside the front part of the nose boom. This special configuration allows for taking undisturbed measurements up to the booms eigenfrequency at $25 \mathrm{~Hz}$. The calculation of the threedimensional wind vector is done in real time using complementary filtered data from the Honeywell Lasernav Inertial Navigation System (INS) mounted at the gravity center of the aircraft, as well as a Novatel
Millennium global positioning system (GPS). The data acquisition frequency is $1 \mathrm{kHz}$, and the output data rate is $100 \mathrm{~Hz}$, which corresponds to a horizontal resolution of $0.65 \mathrm{~m}$.

The same flight pattern was applied during all of the IOPs discussed here. A two-dimensional view of the flight path is presented in Fig. 1b. Within one flight pattern, a vertical profile was flown directly after takeoff at Thruxton airfield in order to determine the actual 
CBL depth $z_{i}$ to which the following straight and level flight legs were adjusted. The horizontal flight legs of $34 \mathrm{~km}$ took about $10 \mathrm{~min}$ each and were oriented in the northeast to southwest direction, heading $40^{\circ} / 220^{\circ}$ and vertically shifted at levels within 0.3 to $1.5 z_{i}$ (Figs. 1c and $2 b$ ). The difference angle between the orientation of the flight legs and the wind direction averaged over the flight leg is mostly less than $\pm 40^{\circ}$ in the CBL (Fig. 2f). Each leg-centered on the wind lidar sitewas flown back and forth, and for each leg, two values are calculated for $l_{w}, \lambda_{m}$, and $\sigma_{w}^{2}$. Note that the $\sigma_{w}^{2}$ values for the forth and back parts of each leg agree by $R^{2}=0.91$. Table 1 provides an overview of the utilized legs and their heights for the various flights. The number of utilized legs is limited by the availability of wind lidar data in the respective height and time interval (at least $50 \%$ has to be available). In total, 34 (32) legs including forth and back are used for the 1-h $(34 \mathrm{~km})$ averaging intervals.

\section{c. Wind lidar measurements}

The wind lidar used for this study is a Lockheed Martin Coherent Technologies 2- $\mu \mathrm{m}$ wind lidar "WindTracer" of the Institute of Meteorology and Climate ResearchDepartment Tropospheric Research (IMK-TRO) of the Karlsruhe Institute of Technology (KIT) (Kalthoff et al. 2013). During the IOPs presented in this study, the wind lidar was operated in vertical stare mode, with the laser pointing into the zenith in order to directly measure the vertical velocity. The wind lidar has a beam diameter of $72 \mathrm{~mm}$ (widening up to $300 \mathrm{~mm}$ depending on the distance from the source) and is emitting $2-\mu \mathrm{m}$ laser pulses of 425-ns duration (pulse length $127.5 \mathrm{~m}$ ) with a repetition frequency of $500 \mathrm{~Hz}$. Heterodyne detection is applied, and the raw data sampling rate of $100 \mathrm{MHz}$ corresponds to data points every $1.5 \mathrm{~m}$ along the beam. The Doppler frequency is determined from a fast Fourier transform (FFT) applying a proprietary automatic peak-finding algorithm. The number of raw data samples used as input for the FFT defines the size of the range gates, from which the average velocity of the scatterers is determined. For our measurements, we used 48 raw data samples as input for the FFT (the rest is zero padded), which corresponds to an independent range gate length of $72 \mathrm{~m}$. A maximum of 100 range gates could be processed. The wind lidar was set up in order to take the first raw data sample at $336 \mathrm{~m}$ above ground level (AGL). The range gate output configuration (i.e., the distance between range gate centers) depends on the maximum measurement range and the number of processed range gates. It varied between the IOPs: on 22 June, the distance between range gate centers was $102 \mathrm{~m}$, while on 27 June and $14 \mathrm{July}$, the range gates were overlapping with a distance of around 33 and $49 \mathrm{~m}$, respectively, between range gate centers. The data acquisition was configured to average each range gate over 500 pulses, resulting in a data rate of $1 \mathrm{~Hz}$. Data with a signal-to-noise ratio lower than $-8 \mathrm{~dB}$ are discarded.

\section{Scaling parameters, averaging intervals, and filters}

\section{a. The convective boundary layer depth and convective velocity scale}

One of the main CBL characteristics is its depth, $z_{i}$, which is also often applied for the scaling of profiles of turbulence quantities. Different methods are in use, either based on vertical profiles from in situ aircraft or radiosonde observations (e.g., Seibert et al. 2000; Beyrich and Leps 2012) or on remote sensing from lidar data (e.g., Träumner et al. 2011). Frequently applied procedures for in situ observations are the parcel method and the maximum gradient method, using virtual potential temperature $\theta_{v}$ or specific humidity $q$ profiles (Beyrich and Leps 2012). The parcel method is based on the assumption that an air parcel from near the surface rises as long as it has positive buoyancy. The level where the air parcel's virtual potential temperature is equal to the environmental virtual potential temperature marks the top of the CBL. We denote the corresponding CBL depth as $z_{i}^{p}$ when the parcel method is used, $z_{i}^{\theta}$ when the temperature gradient is used, and $z_{i}^{q}$ when the specific humidity gradient is used, and we calculate them for the aircraft and radiosonde data. The detection of $z_{i}$ from lidar measurements is done according to Träumner et al. (2011). We apply three different methods to the aerosol backscatter profiles $I_{b}$ : the CBL depth that is determined by the minimum of vertical gradient $\partial I_{b} / \partial z$ is denoted as $z_{i}^{g}$; the one based on fitting an idealized aerosol backscatter profile to the measured profile is denoted as $z_{i}^{i}$; and the one that is based on a threshold separating $I_{b}$ in the CBL from the free atmosphere is denoted as $z_{i}^{k}$. A more detailed description of the algorithms is provided by Träumner et al. (2011).

Using the example of 27 June 2005, the $z_{i}$ values calculated with the aforementioned six different algorithms for aircraft, radiosonde, and lidar data are shown in Fig. 3a. On the average, the three in situ methods differ by less than $50 \mathrm{~m}$ when compared for individual profiles and the three methods based on the backscatter data from the lidar differ by less than $40 \mathrm{~m}$. Figure $3 \mathrm{~b}$ shows the scatterplot relating $z_{i}^{g}$ from lidar to $z_{i}^{\theta}$ from aircraft and radiosondes for all 

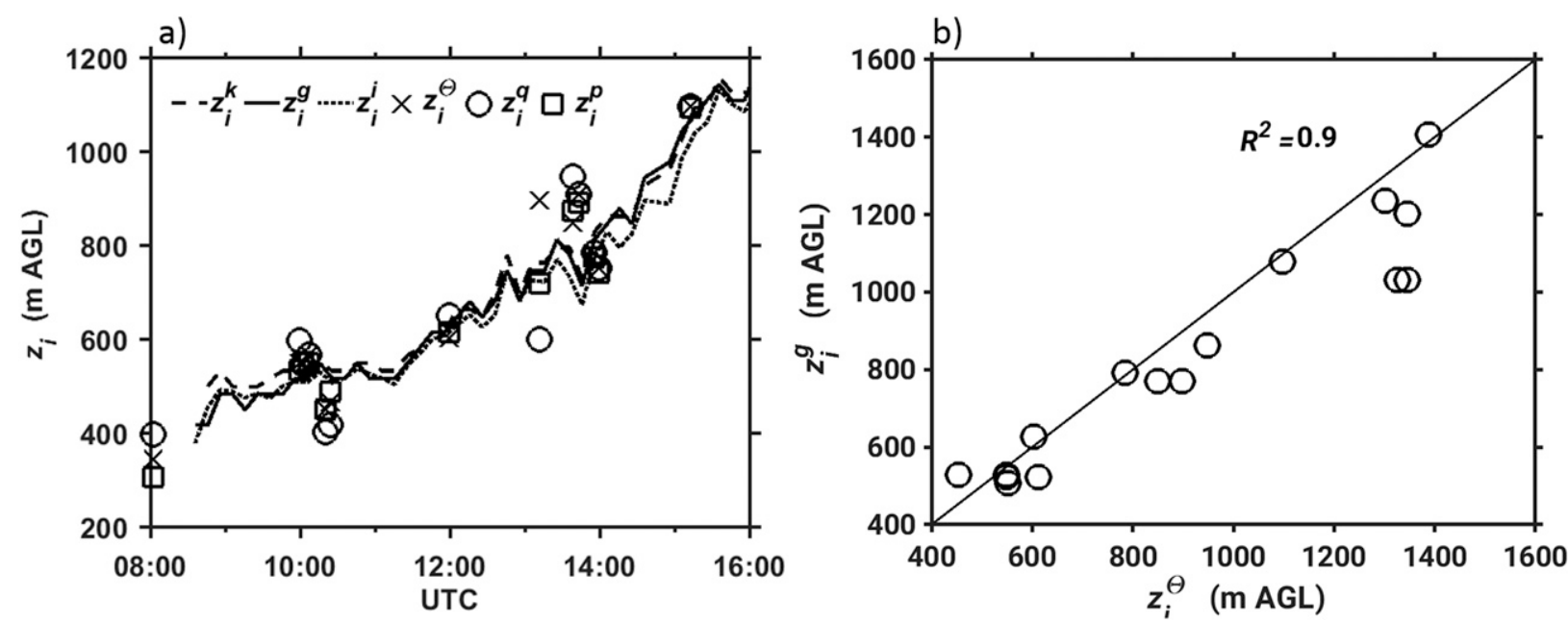

FIG. 3. (a) CBL depth derived with different methods from lidar backscatter profiles (lines) and aircraft and radiosonde profiles (symbols) on 27 Jun 2005. For details, see text. (b) Scatterplot with $z_{i}^{\theta}$ from aircraft and radiosonde virtual potential temperature data vs $z_{i}^{g}$ based on lidar backscatter data for all IOPs.

IOPs, and Table 2 includes the coefficients of determination for the relations between the in situ derived values and the values from lidar. All methods show a satisfactory consistency $\left(R^{2}=0.85\right.$ to 0.92$)$. As continuous $z_{i}$ information are preferable for our investigation, we use $z_{i}^{g}$ (denoted as $z_{i}$ ) for the scaling of the profiles.

The second important scaling parameter is the convective velocity scale $w_{*}$ defined as

$$
w_{*}=\left[g z_{i} H_{0} /\left(\theta \rho c_{p}\right)\right]^{1 / 3} .
$$

Here, $g$ is the acceleration of gravity, $\theta$ is the potential temperature, $\rho$ is the air density, $c_{p}$ is the specific heat capacity of air at constant pressure, and $H_{0}$ is the surface sensible heat flux. To calculate $w_{*}, H_{0}, \theta$, and $\rho$, data from the energy balance station at Chilbolton are used. The $w_{*}$ values averaged for the different flight legs are shown in Fig. 2c. The values range from approximately $1.4 \mathrm{~m} \mathrm{~s}^{-1}$ in the morning up to $1.8 \mathrm{~m} \mathrm{~s}^{-1}$ in the afternoon, which is typical for convective conditions.

TABLE 2. Coefficients of determination, $R^{2}$, between the different methods to determine the CBL depth based on aircraft and radiosonde $\left(z_{i}^{k}, z_{i}^{g}, z_{i}^{i}\right)$ and lidar data $\left(z_{i}^{\theta}, z_{i}^{q}, z_{i}^{p}\right)$. For the lidar data a mean $z_{i}$ value is calculated for \pm 30 min around the start time of the aircraft or radiosonde profile. For details, see section 3a.

\begin{tabular}{cccc}
\hline \hline & $z_{i}^{\theta}$ & $z_{i}^{q}$ & $z_{i}^{p}$ \\
\hline$z_{i}^{k}$ & 0.90 & 0.88 & 0.89 \\
$z_{i}^{g}$ & 0.90 & 0.89 & 0.92 \\
$z_{i}^{i}$ & 0.85 & 0.86 & 0.88 \\
\hline
\end{tabular}

\section{b. Averaging intervals}

For the calculation of CBL characteristics from the lidar, we consider two averaging intervals that are chosen according to typical averaging periods applied to surface and aircraft data. The averaging interval $T$ of turbulent surface quantities needs to fulfil two requirements: on the one hand, it has to be long enough for good statistics, while on the other hand, it has to also be short enough to avoid major nonstationary conditions. The minimum averaging interval can, for example, be determined as the interval for which the statistical error (section 4c) falls below a certain value (Lenschow et al. 1994) or the ogive (i.e., the cumulative integral of the spectrum of $\sigma_{w}^{2}$ ) approaches a constant value (Desjardins et al. 1989). According to Foken et al. (2012), ogives converge within an averaging interval of approximately $30 \mathrm{~min}$ for nearsurface measurements. The second requirement generally limits the interval to about $1 \mathrm{~h}$ (e.g., Wyngaard 1973). Here, we select the upper limit (i.e., $1 \mathrm{~h}$ ) as the first averaging interval for the lidar data. The time averaging intervals are transferred into a corresponding length, $S_{\mathrm{Li}}=t \times \bar{v}_{\mathrm{leg}}$, using the mean wind speed values from aircraft measurements along individual legs $\bar{v}_{\text {leg }}$ (Fig. 2d) as the transfer wind speed. Here and below, the subscript " $\mathrm{Li}$ " indicates variables related to the lidar and the subscript "Do" refers to the aircraft. According to the different wind speed values during the different flights, averaging intervals range from approximately $7 \mathrm{~km}$ (flight A) to $22 \mathrm{~km}$ (flight E) (Fig. 2h). For each $l_{w}, \lambda_{m}$, and $\sigma_{w}^{2}$ value obtained from aircraft measurements for each leg, the corresponding lidar averaging interval is centered on the time when the aircraft passes the site. 
For the second averaging interval, we choose time intervals that correspond to the full length of the flight legs $(S=34 \mathrm{~km})$. Lenschow and Stankov (1986) and Lenschow et al. (1994) suggest flight legs in the order of some decakilometers for the calculation of turbulence quantities. The corresponding lidar averaging intervals are determined according to $T_{\mathrm{Li}}=S / \bar{v}_{\text {leg }}$. Using mean wind speed values prevailing during the individual flight legs (Fig. 2d) results in time averaging intervals that range from approximately $T_{\mathrm{Li}} \approx 1.5 \mathrm{~h}$ (flight E) to nearly $T_{\mathrm{Li}} \approx 5 \mathrm{~h}$ (flight A) (Fig. $2 \mathrm{~g}$ ). Again, the lidar averaging intervals are centered on the times when the aircraft passes the lidar site during each flight leg. Note that these long averaging intervals could be in conflict with the requirement of stationarity, for example, when the CBL is growing considerably in the morning (section $5 b$ ).

\section{c. Filters}

To remove contributions from large-scale trends, we apply a high-pass filter wavelength of $5 \mathrm{~km}$, a value that was also used in other investigations (Kelly et al. 1992; Caramori et al. 1994; Grunwald et al. 1998; Lambert and Durand 1998). This filter also removes possible contributions from mesoscale circulations in the CBL, which may form as a response to surface heterogeneities at length scales greater than $10 \mathrm{~km}$ (Shuttleworth 1988).

According to the Nyquist frequency, the shortest detectable wavelength for the aircraft measurements is $\lambda \geq$ $1.3 \mathrm{~m}$, and for the lidar, depending on $\bar{v}_{\text {leg }}$, it is between 4 and $10 \mathrm{~m}$. When comparing the energy spectra of vertical velocity from lidar measurements with the theoretical $-2 / 3$ slope, we find a considerable loss of energy for a wavelength of $\lambda<100 \mathrm{~m}$. This is around the same order of magnitude as the independent range gate length of $72 \mathrm{~m}$ and related to the beam averaging effect described in the introduction. To make the datasets as comparable as possible, we apply a bandpass filter with wavelengths of $100 \mathrm{~m}$ and $5 \mathrm{~km}$ to the aircraft and lidar data before we calculate $l_{w}, \lambda_{m}$, and $\sigma_{w}^{2}$. To estimate the contributions from wavelengths below $100 \mathrm{~m}$ to $\sigma_{w}^{2}$, which we do not consider, we calculate the relative difference, $d_{\text {Do } 34 \mathrm{~km}}$ :

$$
d_{\mathrm{Do} 34 \mathrm{~km}}=\frac{\sigma_{w \text { DoHP }}^{2}-\sigma_{w \text { Do34km }}^{2}}{\sigma_{w \text { DoHP }}^{2}} .
$$

Here, $\sigma_{w \text { Do } 4 \mathrm{~km}}^{2}$ is calculated from bandpass filtered aircraft data, while $\sigma_{w \text { DoHP }}^{2}$ is calculated from aircraft data that are high-pass filtered only and, thus, include the contributions from wavelengths $<100 \mathrm{~m}$. Figure 4 shows the relative difference as a function of the normalized CBL depth. Below $0.8 z / z_{i}$, the values are mainly between 0.05 and 0.1 . Some larger differences (up to 0.2 ) exist in the upper part of the CBL. This means that

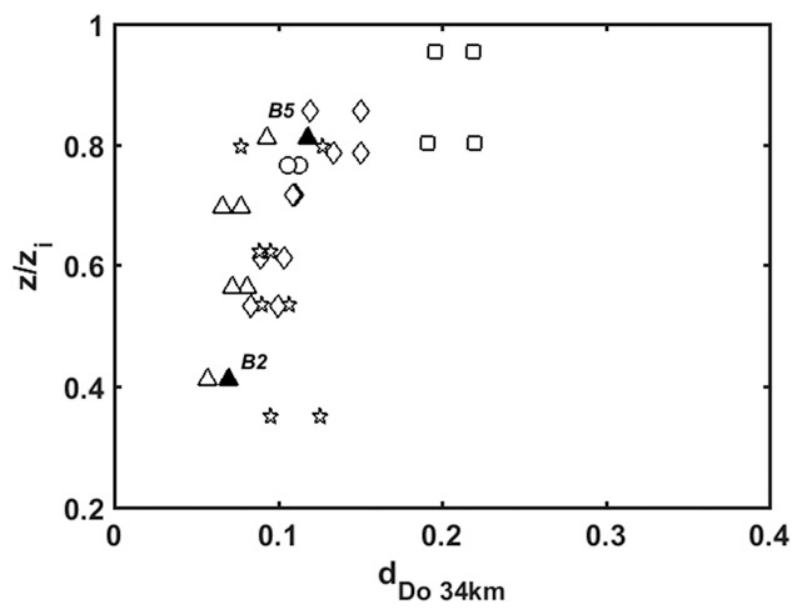

FIG. 4. Relative difference $d_{\text {Do } 34 \mathrm{~km}}$ calculated according to Eq. (2). B2 and B5 indicate values from flight B, flight levels 2 and 5 , respectively (see Table 1 ). The symbols indicate the different flights (circle: flight A, triangle: flight B, square: flight $\mathrm{C}$, diamond: flight D, pentagram: flight E; see Table 1 and Fig. 2).

the loss of energy due to the low-pass filter is usually below $10 \%$.

\section{Comparison of CBL characteristics from lidar and aircraft data}

\section{a. Integral length scale}

The integral length scale $l_{w}$ represents the length scale over which the turbulence (in our case, the vertical velocity) in the CBL remains correlated (e.g., Kaimal and Finnigan 1994). It is defined as

$$
l_{w}=\int_{0}^{\infty} r_{w}(\tau) d \tau
$$

with the space lag $\tau$ and the autocorrelation function

$$
r_{w}(\tau)=\frac{1}{r_{w}(0)} \overline{w(\tau+x) w(x)},
$$

where $w(x)$ denotes vertical velocity and $r_{w}(0)$ is the autocorrelation function at $\tau=0$. According to Lenschow and Stankov (1986), $l_{w}$ can be estimated by integrating the running integral of Eq. (3) up to the first zero crossing of $r_{w}(\tau)$ :

$$
l_{w} \approx \int_{0}^{r_{w} \equiv 0} r_{w}(\tau) d \tau
$$

We estimate $l_{w}$ for the bandpass filtered vertical velocity measurements from aircraft and lidar.

Normalized $l_{w}$ profiles from aircraft, $l_{w \text { Do, and lidar }}$ observations, $l_{w \text { Li }}$, for all flights are included in Fig. 5a. 

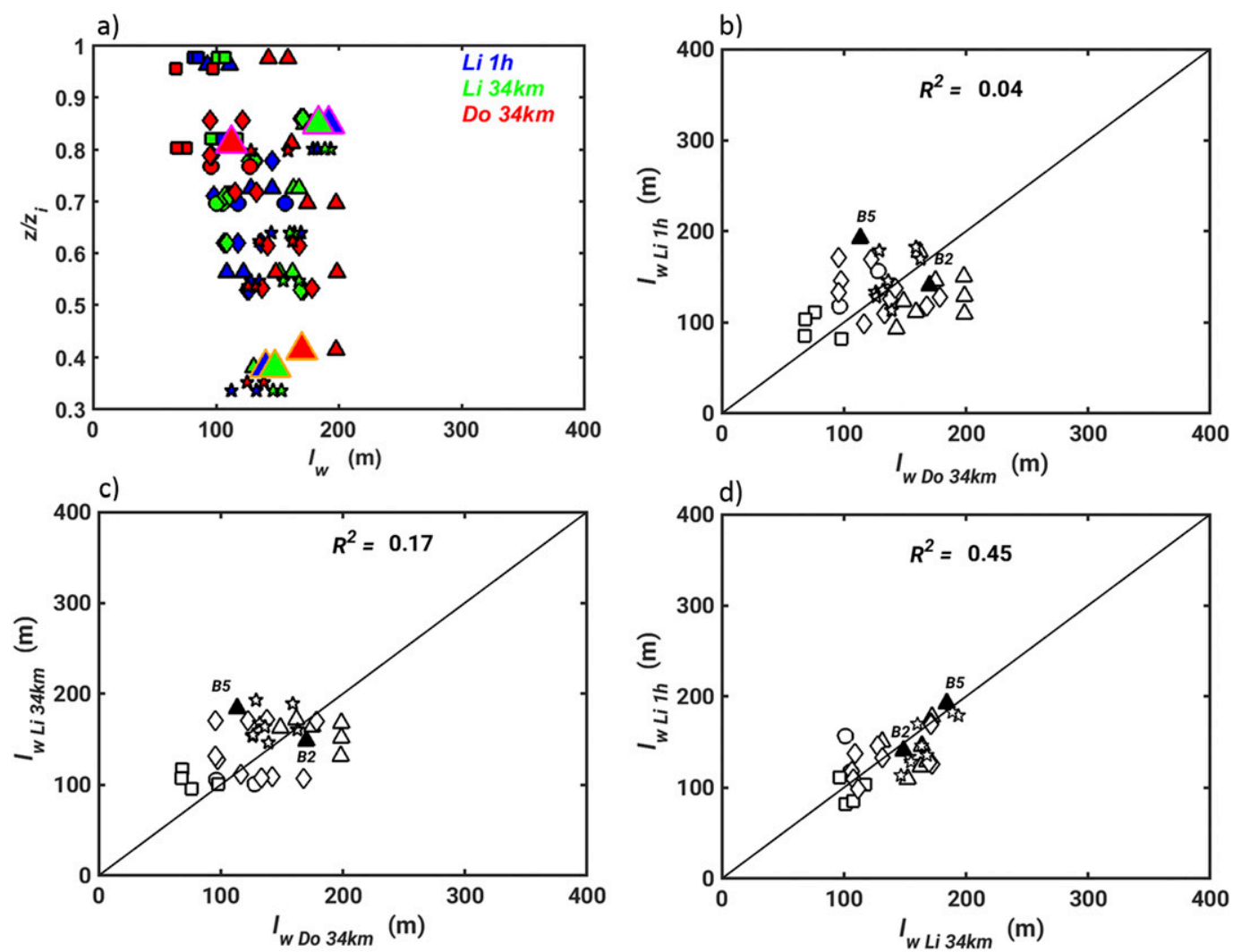

FIG. 5. (a) Normalized profiles of the integral length scale $l_{w}$ for 34-km aircraft (red) and 1-h (blue) and 34-km (green) lidar averaging intervals. (b) Integral length scale based on 1-h lidar vs 34-km aircraft averaging intervals. (c) Integral length scale based on 34-km lidar vs 34-km aircraft averaging intervals. (d) Integral length scale based on 1-h vs 34-km lidar averaging intervals. B2 and B5 in (b)-(d) indicate values from leg B2 and B5 (see Table 1 and Fig. 2). Enlarged triangles in (a) indicate leg B2 (yellow border) and B5 (purple border). For meaning of markers see Fig. 4.

Independent from the observation system, flight leg and averaging interval $(1 \mathrm{~h}, 34 \mathrm{~km})$, the $l_{w}$ values mostly vary between 100 and $200 \mathrm{~m}$. Similar values for the CBL were reported by, for example, Lenschow and Stankov (1986). A considerable scatter exists, and although the $l_{w}$ values indicate a slight decrease toward the top of the CBL, no clear height dependence is evident. The difference between the mean $l_{w}$ values from lidar and aircraft measurements is only $1 \mathrm{~m}(10 \mathrm{~m})$ for 1 -h $(34 \mathrm{~km})$ averaging intervals, while the mean absolute difference $\overline{\left|\Delta l_{w \mathrm{Li} / \mathrm{Do}}\right|}=34 \mathrm{~m}(31 \mathrm{~m})$ is considerably larger (Table 3). Comparing this with the mean $l_{w}$ from lidar and aircraft, $\overline{l_{w \mathrm{~L}} / \mathrm{Do}}=134 \mathrm{~m}(139 \mathrm{~m})$, results in a relative difference of $\overline{\left|\Delta l_{w \mathrm{Li} / \mathrm{Do}}\right|} / \overline{l_{w \mathrm{Li} / \mathrm{Do}}}=0.25$ (0.23). When comparing the $l_{w}$ values for the individual flight legs for the two observation platforms (Figs. 5b,c) and for the two different averaging intervals for the lidar (Fig. 5d), the coefficients of determination indicate poor agreement between $l_{w} \mathrm{Li} 1 \mathrm{~h}$ and $l_{w}$ Do $34 \mathrm{~km}\left(R^{2}=0.04\right)$ as well as $l_{w \mathrm{Li} 34 \mathrm{~km}}$ and $l_{w \text { Do } 34 \mathrm{~km}}\left(R^{2}=0.17\right)$, and moderate agreement between $l_{w \mathrm{Li} 1 \mathrm{~h}}$ and $l_{w \operatorname{Li} 34 \mathrm{~km}}\left(R^{2}=0.45\right)$. This means that on the average $l_{w}$ from both platforms is very similar, while considerable differences occur for individual legs.

\section{b. Spectral peak wavelength}

The wavelength at the spectral peak $\lambda_{m}$ is a parameter of great interest, since it is representative of the size of eddies with the most energy (Kaimal and Finnigan 1994). The $\lambda_{m}$ values were calculated using the mean wavelet energy spectrum $S_{\lambda}$, defined as

$$
S_{\lambda}=\frac{d x}{C_{\psi} N} \sum_{n=0}^{N-1}\left|W^{2}(\lambda, x)\right|^{2}
$$

where $W(\lambda, x)$ is the continuous wavelet transform of the dataset at wavelength $\lambda$ and distance $x, d x$ is the step of distance, and $C_{\psi}$ is the reconstruction factor for the continuous wavelet transform. The wavelet transform is applied by using a Morlet wavelet, and $C_{\psi}$ has a value of 
TABLE 3. Mean values and differences for $l_{w}, \lambda_{m}$, and $\sigma_{w}^{2}$ calculated for 1-h and 34-km averaging intervals (separated by the vertical line). $\overline{x_{\mathrm{Li}}}$ and $\overline{x_{\mathrm{Do}}}$ are the means for lidar and aircraft measurements, respectively, $\overline{x_{\mathrm{Li} / \mathrm{Do}}}$ is the combined mean for lidar and aircraft measurements, $\left|\overline{\left(x_{\mathrm{Li}}\right)}-\overline{\left(x_{\mathrm{Do}}\right)}\right|$ is the absolute difference between the mean values from lidar and aircraft measurements, and $\overline{\left|\Delta x_{\mathrm{Li} / \mathrm{Do}}\right|}=\left(\overline{\left|x_{\mathrm{Li}}-x_{\mathrm{Do}}\right|}\right)$ is the mean absolute difference between the lidar and aircraft measurements, while $x$ stands for $l_{w}, \lambda_{m}$, and $\sigma_{w}^{2}$. The units given in brackets apply to the means and absolute differences. Mean values for the aircraft differ for 1-h and 34-km averaging intervals because of the different number of legs used for the mean.

\begin{tabular}{|c|c|c|c|c|c|c|c|}
\hline & $\overline{x_{\mathrm{Li}}}$ & $\overline{x_{\text {Do }}}$ & $\overline{x_{\mathrm{Li} / \mathrm{Do}}}$ & $\left|\overline{x_{\mathrm{Li}}}-\overline{x_{\mathrm{Do}}}\right|$ & $\overline{\left|\Delta x_{\mathrm{Li} / \mathrm{Do}}\right|}$ & $\overline{\left|\Delta x_{\mathrm{Li} / \mathrm{Do}}\right|} \mid \overline{x_{\mathrm{Li} / \mathrm{Do}}}$ & $\left|\overline{x_{\mathrm{Li}}}-\overline{x_{\mathrm{Do}}}\right| / \overline{x_{\mathrm{Li} / \mathrm{Do}}}$ \\
\hline$l_{w}(\mathrm{~m})$ & $134 \mid 144$ & $135 \mid 134$ & $134 \mid 139$ & $1 \mid 10$ & $34 \mid 31$ & $0.25 \mid 0.23$ & $0.01 \mid 0.07$ \\
\hline$\lambda_{m}(\mathrm{~m})$ & $1162 \mid 1523$ & $1239 \mid 1269$ & $1201 \mid 1396$ & $77 \mid 254$ & $625 \mid 700$ & $0.52 \mid 0.50$ & $0.07 \mid 0.18$ \\
\hline$\sigma_{w}^{2}\left(\mathrm{~m}^{2} \mathrm{~s}^{-2}\right)$ & $0.42 \mid 0.46$ & $0.52 \mid 0.55$ & $0.47 \mid 0.50$ & $0.11 \mid 0.09$ & $0.17 \mid 0.13$ & $0.37 \mid 0.26$ & $0.22 \mid 0.18$ \\
\hline
\end{tabular}

0.776 for this type of wavelet (Torrence and Compo 1998). Figure 6a shows the $\lambda_{m}$ values derived from the energy spectra, both from 34-km aircraft and from 1-h and 34-km lidar data versus the normalized height for all flights. No clear height dependence is evident, neither from the different observation systems nor from the different averaging periods. The $\lambda_{m}$ values mainly group between 500 and $2000 \mathrm{~m}$, with the lower values preferentially occurring at the CBL top. With $z_{i}$ values between $500 \mathrm{~m}$ and $1.5 \mathrm{~km}$ (Fig. 2a), these values are similar to previous results, for example, those of Kaimal et al. (1976) and Caughey and Palmer (1979), who found a relation of $\lambda_{m} \approx 1.5 z_{i}$ around the center of the CBL. As for $l_{w}$, the difference between the mean $\lambda_{m}$ values from lidar and aircraft measurements is with $77 \mathrm{~m}$ $(254 \mathrm{~m})$ for 1 -h $(34 \mathrm{~km})$ averaging intervals much smaller than the mean absolute difference $\overline{\left|\Delta \lambda_{m \mathrm{Li} / \mathrm{Do}}\right|}=625 \mathrm{~m}$ $(700 \mathrm{~m})$ (Table 3). This means that the relative mean absolute difference is as high as $0.52(0.50)$. Figures $6 \mathrm{~b}$ and $6 \mathrm{c}$ show scatterplots of $\lambda_{m}$ Do $34 \mathrm{~km}$ and $\lambda_{m} \mathrm{Li1h}$ and $\lambda_{m \mathrm{Li}} 34 \mathrm{~km}$, respectively, and Fig. 6d of $\lambda_{m} \mathrm{Li} 1 \mathrm{~h}$ and $\lambda_{m \mathrm{Li} 34 \mathrm{~km}}$ for the individual flight legs. Overall, the
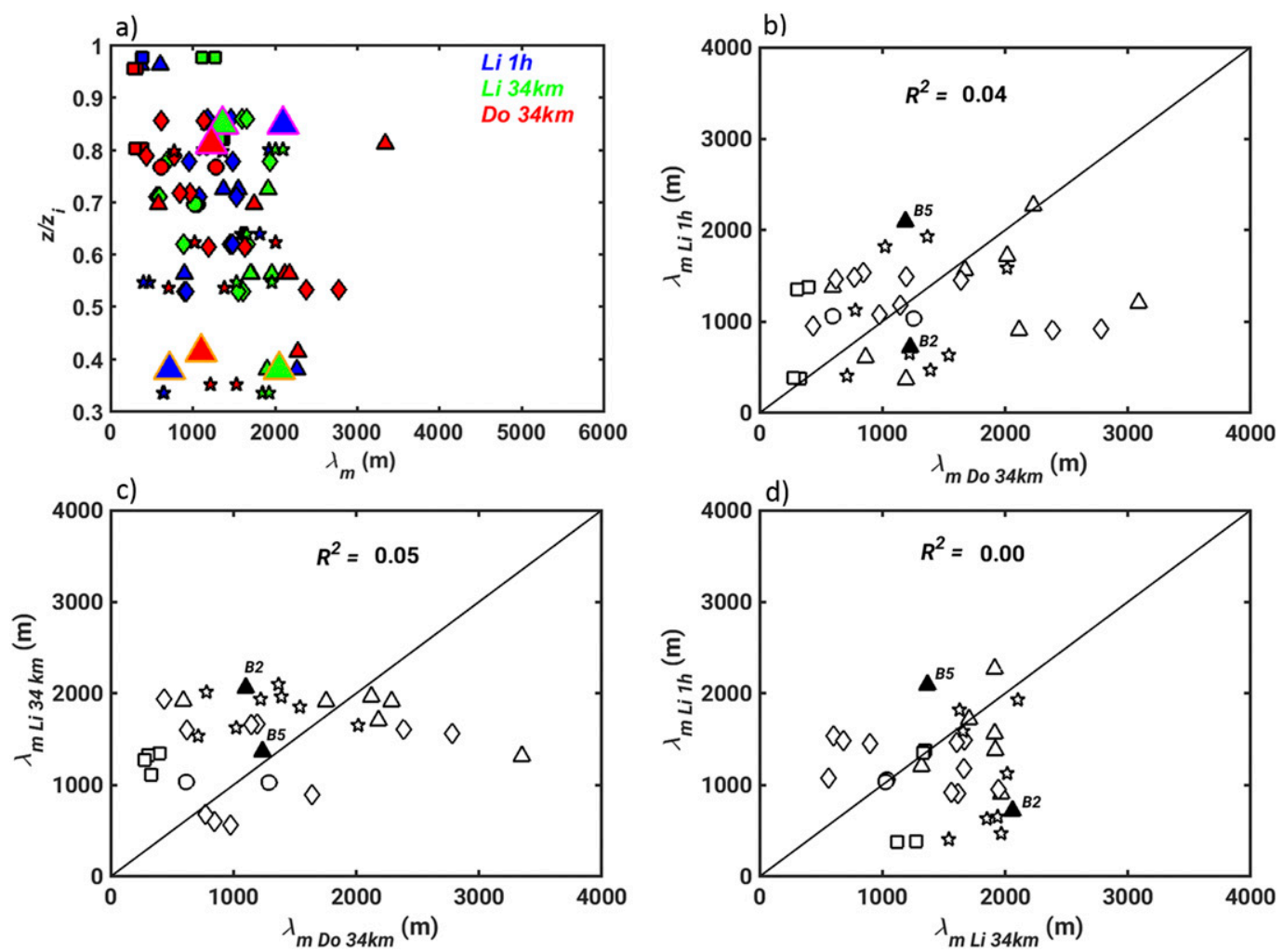

FIG. 6. (a) Normalized profiles of the spectral peak wavelength of the vertical velocity energy spectrum $\lambda_{m}$ for $34-\mathrm{km}$ aircraft (red) and 1-h (blue) and 34-km (green) lidar averaging intervals. (b) $\lambda_{m}$ based on 1-h lidar vs 34-km aircraft averaging intervals. (c) $\lambda_{m}$ based on 34-km lidar vs 34-km aircraft averaging intervals. (d) $\lambda_{m}$ based on 1-h lidar vs 34-km lidar averaging intervals. B2 and B5 in (b)-(d) indicate values from legs B2 and B5 (see Table 1 and Fig. 2). Enlarged triangles in (a) indicate leg B2 (yellow border) and B5 (purple border). For meaning of markers see Fig. 4. 

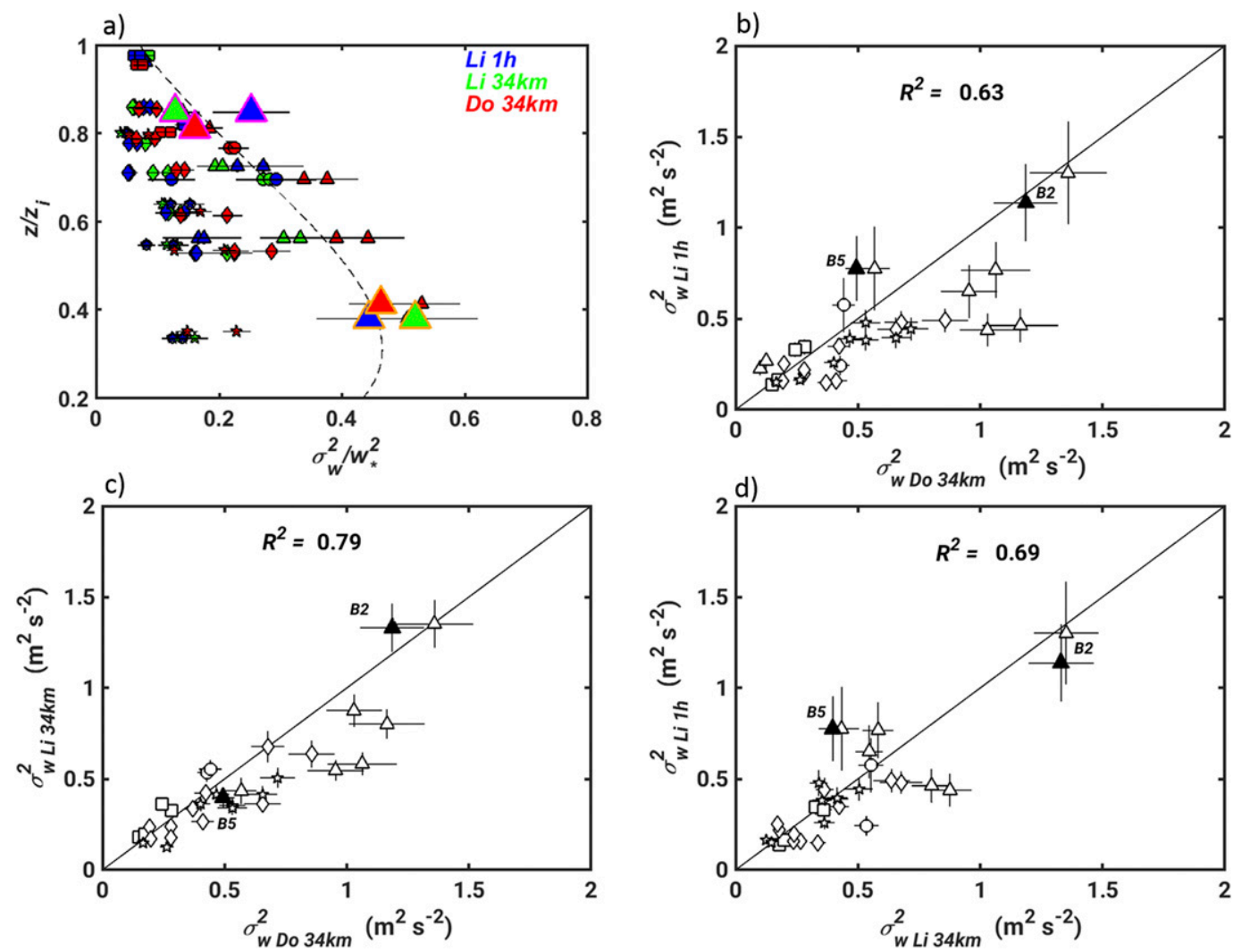

FIG. 7. (a) Normalized variance profiles of vertical velocity $\sigma_{w}^{2}$ for 34-km aircraft (red) and 1-h (blue) and 34-km (green) lidar averaging intervals. The dashed line represents the parameterization [Eq. (11)] proposed by Lenschow et al. (1980). (b) $\sigma_{w}^{2}$ based on 1-h lidar vs 34-km aircraft averaging intervals. (c) $\sigma_{w}^{2}$ based on 34-km lidar vs 34-km aircraft averaging intervals. (d) $\sigma_{w}^{2}$ based on 1-h lidar vs 34-km lidar averaging intervals. The straight lines show the statistical error [Eq. (10)]. B2 and B5 in (b)-(d) indicate values from legs B2 and B5 (see Table 1 and Fig. 2). Enlarged triangles in (a) indicate legs B2 (yellow border) and B5 (purple border). For meaning of markers see Fig. 4.

coefficients of determination indicate very poor agreement for all combinations $\left(R^{2} \leq 0.05\right)$.

\section{c. Vertical velocity variance}

We calculate the vertical velocity variance from the vertical velocity fluctuation $w^{\prime}(x)$ as

$$
\sigma_{w}^{2}=\overline{w^{\prime}(x) w^{\prime}(x)}
$$

and carry out error estimates for $\sigma_{w}^{2}$ according to Lenschow and Kristensen (1985) and Lenschow et al. (1994). The systematic error for $\sigma_{w}^{2}$ is calculated by

$$
\epsilon_{\mathrm{sys}} \approx 2 \sigma_{w}^{2} \frac{l_{w}}{S},
$$

and the random error is determined as

$$
\epsilon_{\text {rand }} \approx \sigma_{w}^{2} \sqrt{2 \frac{l_{w}}{S}} .
$$

The total statistical error amounts to

$$
\epsilon_{\text {stat }}=\epsilon_{\text {sys }}+\epsilon_{\text {rand }} .
$$

On the average, $\epsilon_{\mathrm{sys}}$ is about 10 times smaller than $\epsilon_{\text {rand }}$, and $\epsilon_{\text {stat }}$ is $0.06 \mathrm{~m}^{2} \mathrm{~s}^{-2}$ for the aircraft and $0.08 \mathrm{~m}^{2} \mathrm{~s}^{-2}$ $\left(0.05 \mathrm{~m}^{2} \mathrm{~s}^{-2}\right)$ for the lidar data using $1-\mathrm{h}(34 \mathrm{~km})$ averaging intervals. With respect to the mean $\sigma_{w}^{2}$ values of lidar and aircraft (Table 3), $\epsilon_{\text {stat }}$ is $11 \%$ for the aircraft and $19 \%(11 \%)$ for the lidar. The normalized $\sigma_{w}^{2}$ profiles with error bars indicating $\epsilon_{\text {stat }}$ calculated for aircraft and lidar data for both averaging intervals are shown in Fig. 7a. The $\sigma_{w}^{2}$ values approximately resemble the vertical distribution as known from textbooks (e.g., Lenschow et al. 1980):

$$
\frac{\sigma_{w}^{2}}{w_{*}^{2}}=1.8\left(\frac{z}{z_{i}}\right)^{2 / 3}\left[1-0.8\left(\frac{z}{z_{i}}\right)\right]^{2} ;
$$

that is, the values are higher in the middle part of the CBL and decrease toward the CBL top. The considerable spread of $\sigma_{w}^{2}$ values is comparable to other observational studies based on in situ measurements (e.g., Kaimal et al. 

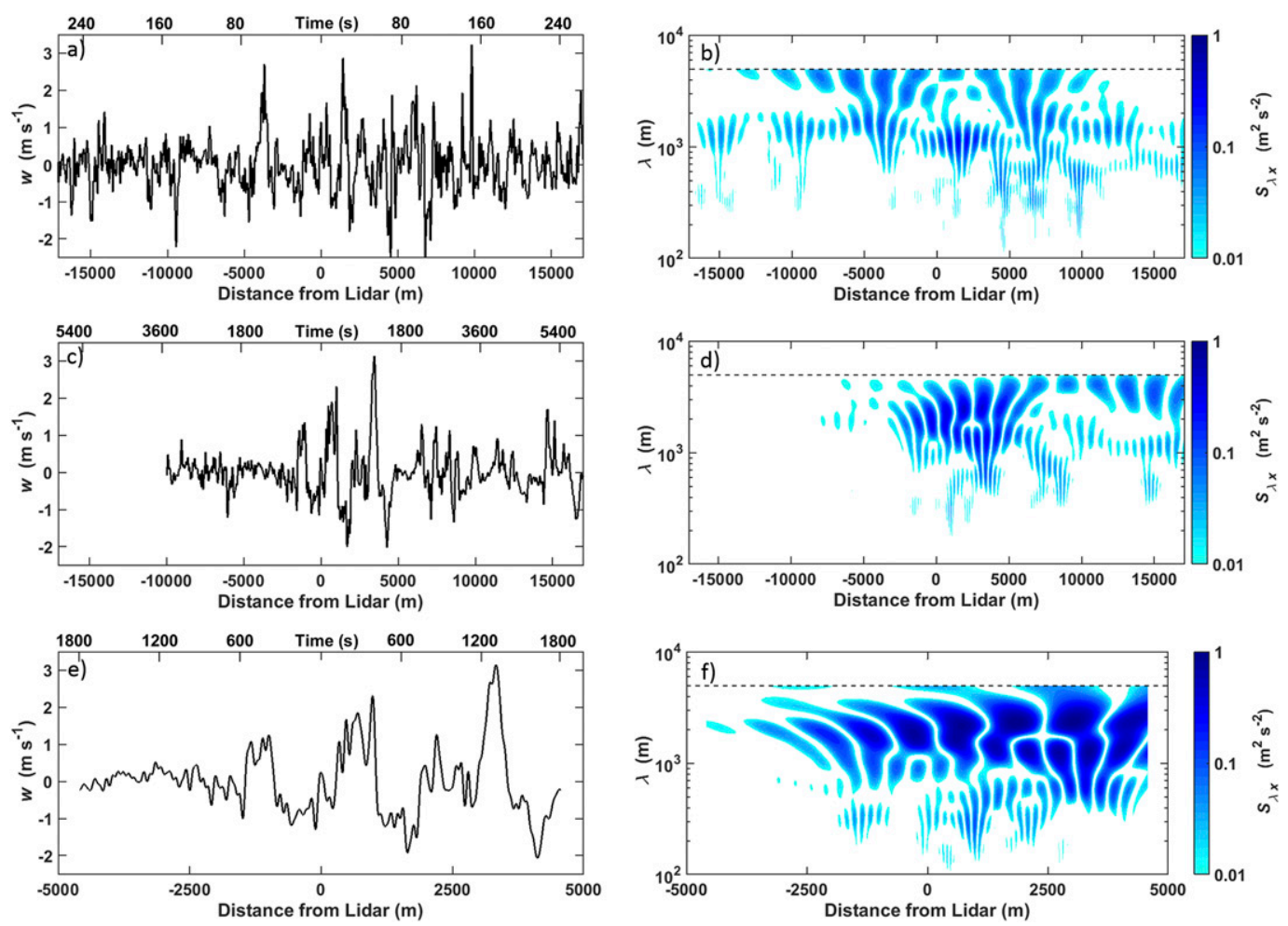

FIG. 8. Vertical velocity from (a) aircraft (34-km averaging interval), (c) lidar for 34-km averaging interval (some data are missing for the 34-km section), and (e) lidar for 1-h averaging interval. (b),(d),(f) Corresponding wavelet energy spectrums. All data are from flight B5 (flight B, leg 5; see Table 1 and Fig. 2).

1976; Caughey and Palmer 1979), wind lidar measurements (e.g., Maurer et al. 2016), and on aircraft measurements (e.g., Drüe and Heinemann 2002). The mean absolute difference $\overline{\left|\Delta \sigma_{w \mathrm{Li} / \mathrm{Do}}^{2}\right|}=0.17 \mathrm{~m}^{2} \mathrm{~s}^{-2}\left(0.13 \mathrm{~m}^{2} \mathrm{~s}^{-2}\right)$ is around 2.5 times as large as the mean statistical error $\overline{\epsilon_{\text {stat Li} / \mathrm{Do}}}=0.07 \mathrm{~m}^{2} \mathrm{~s}^{-2}\left(0.05 \mathrm{~m}^{2} \mathrm{~s}^{-2}\right)$ using 1 -h $(34 \mathrm{~km}) \mathrm{av}-$ eraging intervals. The coefficients of determination are $R^{2}=0.63$ for $\sigma_{w \text { Do } 34 \mathrm{~km}}^{2}$ versus $\sigma_{w \text { Li 1h }}^{2}$ values (Fig. $7 \mathrm{~b}$ ) and $R^{2}=0.79$ for $\sigma_{w \text { Do } 34 \mathrm{~km}}^{2}$ versus $\sigma_{w \mathrm{Li} 4 \mathrm{~km}}^{2}$ (Fig. $7 \mathrm{c}$ ); that is, the coefficients are considerably higher than for $l_{w}$ and $\lambda_{m}$ (sections 4a, 4b). Comparing 1-h and 34-km averaging intervals from the lidar, we also obtain a reasonable agreement $\left(R^{2}=0.69\right.$; Fig. $\left.7 \mathrm{~d}\right)$. Despite some scatter around the $1: 1$ line, most of the $\sigma_{w}^{2}$ values from aircraft are higher than the ones from lidar (Figs. 7b,c), which is also reflected in the mean $\sigma_{w}^{2}$ values (Table 3 ).

\section{Possible reasons for observed differences between lidar and aircraft data}

To illustrate how the differences in CBL characteristics between the aircraft and lidar data for individual legs come about, we start with taking a closer look at flight B, leg 5 (leg B5; Table 1 and Fig. 2). As visible in
Figs. 5, 6, and 7, differences occur in $l_{w}, \lambda_{m}$, and $\sigma_{w}^{2}$ values of leg B5 between aircraft and lidar data, which also depend on the used averaging interval. For example, the $\sigma_{w}^{2}$ values from lidar data are larger than the values from the aircraft data when using 1-h averaging intervals (Fig. 7b) and smaller for the 34-km averaging interval (Fig. 7c). Figures $8 \mathrm{a}$ and $8 \mathrm{~b}$ show the vertical velocity data from aircraft, and the corresponding spacedependent energy spectrum from wavelet analysis, respectively. In the aircraft data, strong convective activity is present from around -5 - to $+10-\mathrm{km}$ distance from the lidar, with wavelengths on the order of some kilometers containing most of the energy. Less convection at those wavelengths occurs outside that range, so that the variance for the whole averaging interval amounts up to $\sigma_{w}^{2}=0.49 \mathrm{~m}^{2} \mathrm{~s}^{-2}$ (Figs. $7 \mathrm{~b}, \mathrm{c}$ ). Looking at the corresponding lidar data for the 34-km averaging interval (Figs. 8c,d), several successive strong convective cells (convective cluster) with updrafts of $1-3 \mathrm{~m} \mathrm{~s}^{-1}$ between around -2 - to $5-\mathrm{km}$ distance from the lidar dominate the vertical velocity pattern. The convection before and behind this convective cluster is much weaker. This means that the energy mainly contributing to $\sigma_{w}^{2}$ is confined only to a rather short section and that cells with wavelengths $>1 \mathrm{~km}$ strongly contribute to $\sigma_{w}^{2}$. 
In total, the variance for the whole averaging interval is moderate $\left(\sigma_{w}^{2}=0.40 \mathrm{~m}^{2} \mathrm{~s}^{-2} ;\right.$ Fig. $\left.7 \mathrm{c}\right)$. Instead of looking at $34-\mathrm{km}$ averaging intervals, we now consider $1-\mathrm{h}$ averaging intervals for the lidar (Figs. 8e,f). This 1-h averaging interval corresponds to an absolute distance of less than $10 \mathrm{~km}$ (Fig. 2h) and includes mostly the section with the convective cluster, which results in a quite high variance $\left(\sigma_{w}^{2}=0.78 \mathrm{~m}^{2} \mathrm{~s}^{-2}\right.$; Fig. $\left.7 \mathrm{~b}\right)$. The differences in $\sigma_{w}^{2}$ between aircraft and lidar data are larger than the respective statistical errors (Figs. 7b,c). In this example, the $\sigma_{w}^{2}$ values from the lidar strongly depend on the location of the convective cluster in the sample. If the convective cluster was outside the 1-h averaging interval, $\sigma_{w}^{2}$ would be much smaller, while it stayed the same for the 34-km averaging interval. In this example, $l_{w}$ from lidar is similar for both averaging intervals and about twice as large as $l_{w}$ from the aircraft (Figs. 5a-c), and $\lambda_{m}$ from lidar for the 1-h averaging interval is with $2097 \mathrm{~m}$ nearly twice the size than $\lambda_{m}$ from aircraft and from lidar for the 34-km averaging interval (Figs. 6a-c), which is in agreement with the wavelet energy spectrums in Figs. 8b, 8d, and 8f.

In the introduction, we listed several reasons that could be responsible for differences of CBL characteristics from aircraft and lidar observations. Because of the applied bandpass filter (section 3c), the effect of beam averaging on the turbulence spectrum of the lidar can be ruled out as a cause. In the following, we first investigate how $l_{w}, \lambda_{m}$, and $\sigma_{w}^{2}$ values from lidar data depend on the transfer wind speed (i.e., the horizontal wind speed used for the transfer from time to space). Then we assess nonstationary or heterogeneous conditions as possible explanations for the observed differences between lidar and aircraft data. In a last step, we address the dependency of the statistical error of $\sigma_{w}^{2}$ on $l_{w}$.

\section{a. Effect of horizontal wind speed used for the transfer from time to space}

When transferring the lidar data from time to space, we calculate a mean horizontal wind speed for each individual leg calculated from the aircraft data (section $3 b$ ), which is (slightly) different for the individual heights (Fig. 2d). This a critical assumption as the cells do not necessarily travel with the mean wind speed in the respective height (e.g., Powell and Elderkin 1974) and the wind speed might change during the time averaging interval used for the lidar. Using a too-large or too-small transfer wind speed value results in stretching or compression of the cells in the sample. Furthermore, the overall length of the lidar time series used for the 34-km averaging intervals depends on the used transfer wind speed (it is longer for a smaller transfer wind speed and shorter for a larger transfer wind speed). In the following, we investigate the sensitivity of $l_{w}, \lambda_{m}$, and $\sigma_{w}^{2}$ from lidar data on the transfer wind speed. Therefore, we determine a mean horizontal wind speed value in the CBL $\bar{v}_{\mathrm{CBL}}$ for each flight and consider its variability by adding and subtracting its standard deviation $\sigma_{\bar{v}_{\mathrm{CBL}}}$.

The correlations between $l_{w}$ and $\lambda_{m}$ calculated with $\bar{v}_{\text {leg }}\left(l_{w \text { leg }}\right.$, and $\left.\lambda_{m \text { leg }}\right)$ and $l_{w}$ and $\lambda_{m}$ calculated with $\bar{v}_{\mathrm{CBL}}$ $\left(l_{w} \mathrm{CBL}\right.$ and $\left.\lambda_{m \mathrm{CBL}}\right)$ are quite high $\left(R^{2}=0.87\right.$ and $R^{2}=$ 0.79 ) for 1-h averaging intervals (Figs. 9a,c). This is not surprising as the differences between $\bar{v}_{\mathrm{CBL}}$ and $\bar{v}_{\text {leg }}$ are rather small on the average $\left(<0.15 \mathrm{~m} \mathrm{~s}^{-1}\right.$; Fig. $\left.2 \mathrm{~d}\right)$. For $\bar{v}_{\mathrm{CBL}}>\bar{v}_{\text {leg }}, l_{w \mathrm{CBL}}$ and $\lambda_{m \mathrm{CBL}}$ generally are larger than $l_{w \text { leg }}$ and $\lambda_{m \text { leg }}$ (blue markers) and vice versa (red markers), which is in agreement with the stretching and compression of the cells. The spread of $l_{w}$ for individual legs, which results from using $\bar{v}_{\mathrm{CBL}} \pm \sigma_{\bar{v}_{\mathrm{CBL}}}$ (indicated by the error bars in Fig. 9a), is $41 \mathrm{~m}$ on the average (about 0.30 when divided by the mean $l_{w} \mathrm{CBL}$ of $134 \mathrm{~m}$ ). This is more than the mean absolute difference in $l_{w}$ between lidar and aircraft data of $34 \mathrm{~m}$ (section $4 \mathrm{a}$ and Table 3 ). For $\lambda_{m}$, the mean spread is $390 \mathrm{~m}$ ( 0.31 when divided by the mean $\lambda_{m \mathrm{CBL}}$ of $\left.1246 \mathrm{~m}\right)$ (Fig. 9c), which is less than the mean absolute difference from lidar and aircraft data of $625 \mathrm{~m}$ (section $4 \mathrm{~b}$ and Table 3). For individual legs, $l_{w}$ and $\lambda_{m}$ are in general sensitive to the transfer wind speed value. This is evident from the triplets (three markers connected by a line represent one leg) in Figs. 9b and 9d for which the gradient $\Delta l_{w} / \Delta v$ is positive. The sensitivity is larger for smaller $\bar{v}_{\mathrm{CBL}}$. There are few legs where $l_{w}$ and $\lambda_{m}$ do not follow the systematic behavior. This is related to the uncertainty of the method (i.e., an autocorrelation function approaching but not crossing zero for $l_{w}$ and two maxima of similar magnitude in the wavelet energy spectrum for $\lambda_{m}$ ). The results are qualitatively the same when using $34-\mathrm{km}$ averaging intervals. These sensitivity tests indicate that $l_{w}$ and $\lambda_{m}$ strongly depend on the transfer wind speed. Thus, erroneous assumptions for this wind speed could partly explain the large differences in $l_{w}$ and $\lambda_{m}$ from aircraft and lidar (sections 4a, 4b and Figs. 5, 6).

For $\sigma_{w}^{2}$, it does not matter if the cells are stretched or compressed as long as they are composed in the averaging interval. Consequentially, there is no sensitivity of $\sigma_{w}^{2}$ on the transfer wind speed for the 1-h averaging intervals and only a weak sensitivity for the 34-km averaging intervals (because the sample length depends on the transfer wind speed).

\section{b. Nonstationarity and heterogeneity}

The range around the lidar position for which aircraft and lidar detect the same convective structures is 

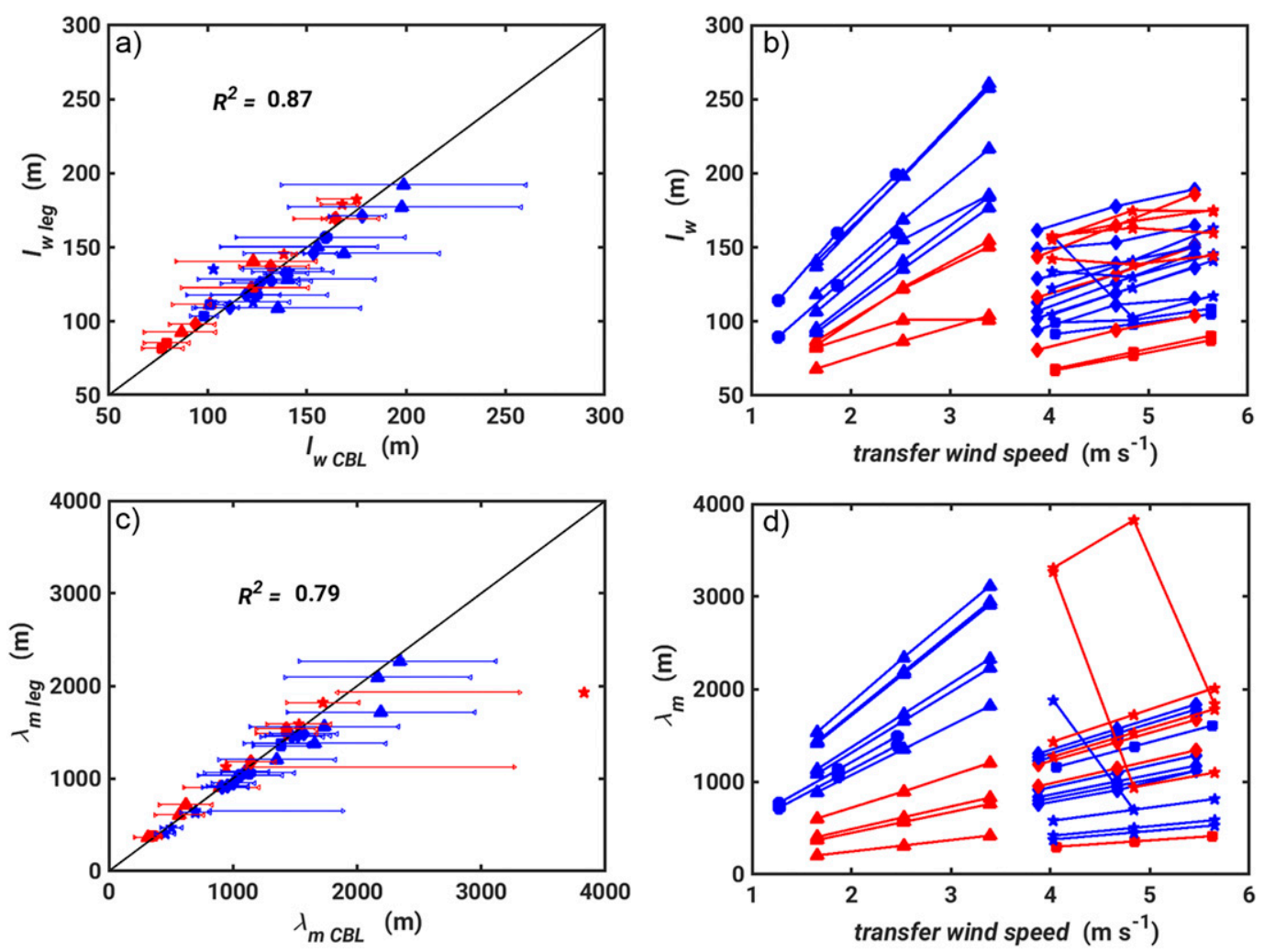

FIG. 9. (a) Integral length scale $l_{w \text { leg }}$ and (c) spectral peak wavelength $\lambda_{m}$ leg calculated using transfer wind speeds different for individual legs vs integral length scale $l_{w \mathrm{CBL}}$ and spectral peak wavelength $\lambda_{m}$ CBL calculated for 1-h averaging intervals using a mean transfer wind speed for the whole CBL. The error bars indicate the spreads in $l_{w}$ and $\lambda_{m}$, which result from using $\bar{v}_{\mathrm{CBL}} \pm \sigma_{\bar{v}_{\mathrm{CBL}}}$ to calculate $l_{w}$ and $\lambda_{m}$. (b) Relationship between $l_{w}$ and transfer wind speed and (d) relationship between $\lambda_{m}$ and transfer wind speed. Each triplet belongs to one leg and consists of the three $l_{w}$, respectively, $\lambda_{m}$ values, which result when using $\bar{v}_{\mathrm{CBL}} \pm \sigma_{\bar{v}_{\mathrm{CBL}}}$ to calculate $l_{w}$ and $\lambda_{m}$. The blue color indicates legs for which $\bar{v}_{\mathrm{CBL}}>\bar{v}_{\text {leg }}$ and the red color marks legs for which $\bar{v}_{\mathrm{CBL}}<\bar{v}_{\text {leg }}$. For meaning of markers see Fig. 4.

expected to be limited and to depend on the cell size. To investigate this, we calculate the correlation between vertical velocity from lidar and aircraft data as a function of the distance from the lidar. For this, we start with a distance of $\pm 1 \mathrm{~km}$ and increase the distance in both directions continuously. In Fig. 10a, the vertical velocity and correlation function for a distance up to $\pm 5 \mathrm{~km}$ for flight B, leg 2 (leg B2) is shown. The shown sample length is approximately the same as used for the 1-h averaging intervals for the lidar (Fig. 2h). The vertical velocity values from lidar and aircraft in the immediate surroundings of Chilbolton agree quite well. A convective cell with a vertical velocity of up to $w=2 \mathrm{~m} \mathrm{~s}^{-1}$ and of a width of approximately $500 \mathrm{~m}$ is present just before the aircraft crossed the lidar (A: peak at $-700 \mathrm{~m})$. However, toward the end of the displayed distance, the cell structures become more and more different, although some greater cells are still visible in both datasets (B: peak at $-3 \mathrm{~km}$; C: positive vertical velocity values between 4 and $5 \mathrm{~km}$ ). This is also reflected in the correlation coefficient, which is approximately $r=0.7$ for the initial distance of about $\pm 1 \mathrm{~km}$, and is about $r=0.5$ at the distance of $\pm 5 \mathrm{~km}$. The $\sigma_{w}^{2}$ values calculated from lidar and aircraft for the shown sample are similar $\left(\sigma_{w \mathrm{Li}}^{2}=1.13 \mathrm{~m}^{2} \mathrm{~s}^{-2}\right.$ and $\left.\sigma_{w \text { Do }}^{2}=1.24 \mathrm{~m}^{2} \mathrm{~s}^{-2}\right)$, which is in agreement with the rather high coherence.

More detailed information about the space-varying coherence of the lidar and aircraft data as a function of wavelength provides a wavelet analysis (KronlandMartinet et al. 1987). For example, Treviño and Andreas (1996), Attié and Durand (2003), and Mauder et al. (2007) applied this technique to time series. We use the analytic Morlet wavelet for coherence computation. As the energy spectrum [Eq. (6)] is of primary interest, the magnitude-squared coherence between the aircraft and lidar data is estimated (Fig. 10b). While there is little coherence at shorter wavelengths $(\lambda \leq 200 \mathrm{~m})$, even within the immediate surroundings of the lidar, strong coherence $(\geq 0.6)$ 

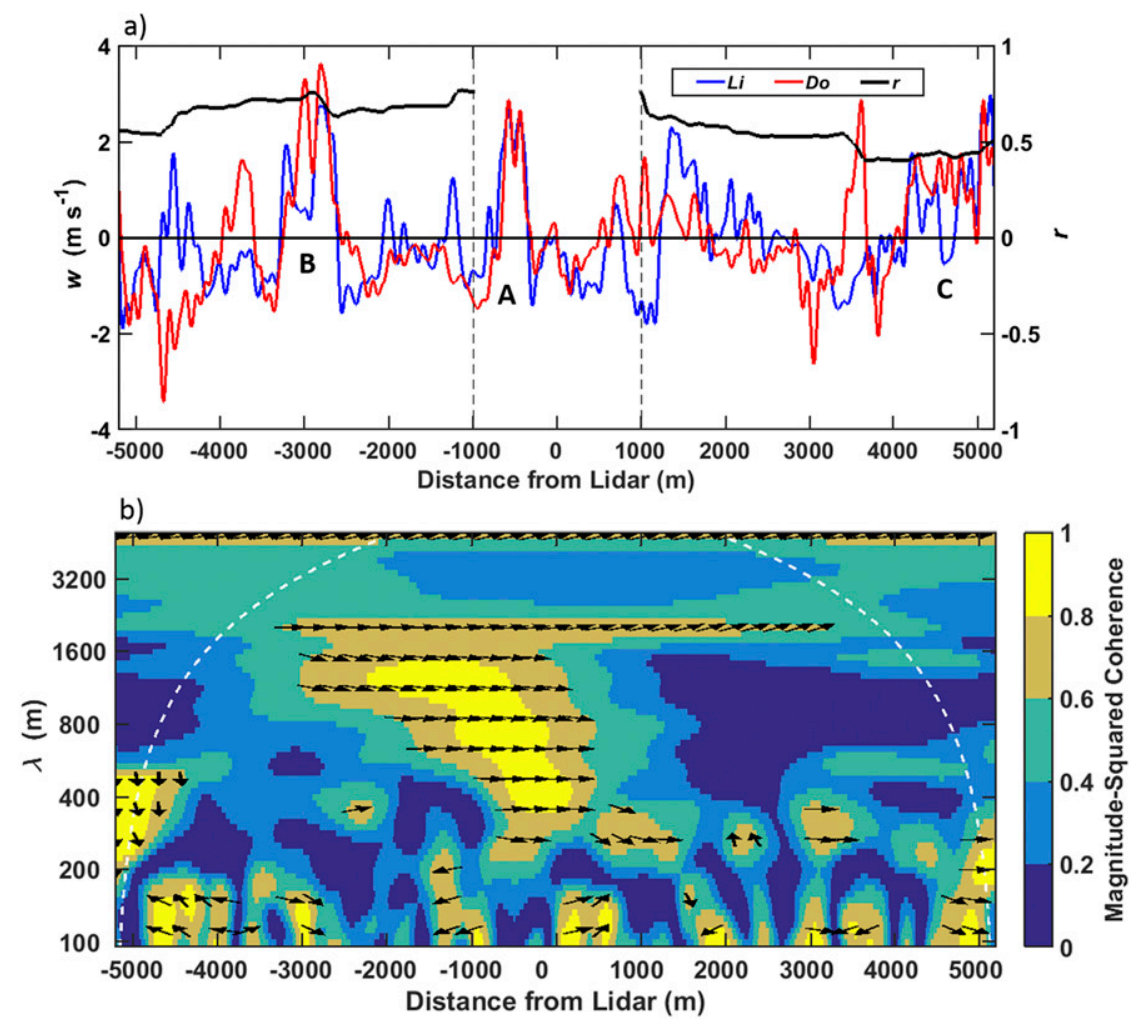

FIG. 10. (a) Vertical velocity from aircraft and lidar, as well as the correlation function $r$, from flight B2 (flight B, leg 2; see Table 1 and Fig. 2) and (b) wavelet coherence between vertical velocity from lidar and aircraft. In (b), the arrows indicate the phase shift (only given for coherences $>0.6$ ) between the vertical velocities from aircraft and lidar. An arrow pointing to the right (left) corresponds to $0^{\circ}\left(180^{\circ}\right)$ phase shift. The dashed white line indicates the cone of influence. A, B, and C in (a) mark cells discussed in the text.

without phase shift is found for wavelengths between approximately $\lambda=200$ and $1500 \mathrm{~m}$ up to a distance of around -2 to $0.5 \mathrm{~km}$ from the lidar. Convective cells with wavelengths around $\lambda=2 \mathrm{~km}$ even show a good coherence within a distance of around $\pm 3 \mathrm{~km}$. Overall, these results indicate that Taylor's hypothesis is better applicable for larger cells, which is in agreement with previous studies by, for example, Powell and Elderkin (1974) and Higgins et al. (2012). However, the distance over which we find coherence is larger than the distances reported by Powell and Elderkin (1974), who report coherence in the surface layer over distances not longer than the along-wind dimension of the cells.

The averaging intervals are generally longer (Fig. 2h) than the distance over which we can expect coherence of the lidar and aircraft data. However, if turbulence was homogeneous along the flight leg (statistically the same at every point) and if turbulence was stationary during the lidar averaging interval (statistically not changing over time), CBL characteristics derived from lidar and aircraft should be the same. As we found that this is not the case (section 4), we (i) examine how homogenous/stationary the aircraft and lidar data are and (ii) investigate if the large differences in $l_{w}, \lambda_{m}$, and $\sigma_{w}^{2}$ values between aircraft and lidar data for individual legs are related to nonstationary or heterogeneous conditions during the averaging intervals. For this, we calculate the nonstationarity ratio (NR) after Mahrt (1998) for $\sigma_{w}^{2}$ on individual legs. The whole sample is divided into $I$ records, which in turn are divided into $J$ subrecord segments, and the "between record" standard deviation,

$$
\sigma_{\mathrm{btw}}=\sqrt{\frac{1}{I-1} \sum_{i=1}^{I}\left[\overline{\sigma_{w}^{2}}(i)-\overline{\sigma_{w}^{2}}\right]^{2}},
$$

and the "within record" standard deviation,

$$
\sigma_{\mathrm{wi}}(i)=\sqrt{\frac{1}{J-1} \sum_{j=1}^{J}\left[\sigma_{w}^{2}(i, j)-\overline{\sigma_{w}^{2}}(i)\right]^{2}}
$$



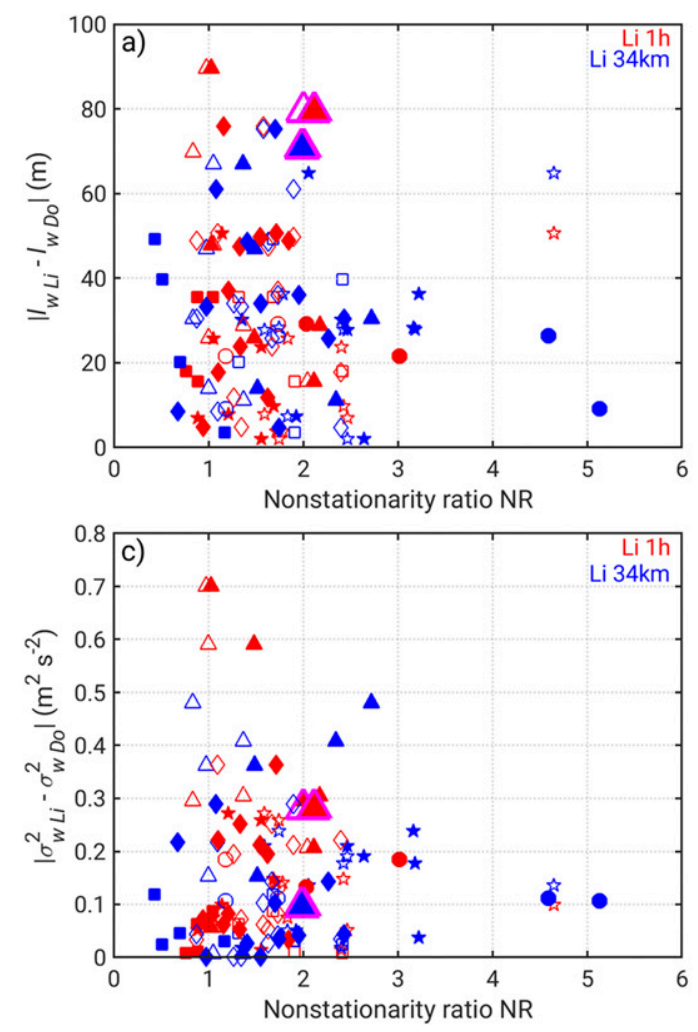

are calculated, where $\sigma_{w}^{2}(i, j)$ is the variance for the $j$ th segment of the $i$ th record, $\overline{\sigma_{w}^{2}}(i)$ is the average of $\sigma_{w}^{2}(i, j)$ for the $i$ th record, and $\frac{w}{\sigma_{w}^{2}}$ is the average over all segments and records. The $\sigma_{\mathrm{wi}}(i)$ is computed for each of the $I$ records and averaged afterward. The nonstationarity ratio is then calculated as

$$
\mathrm{NR}=\frac{\sigma_{\mathrm{btw}}}{\sigma_{\mathrm{wi}}} \sqrt{J}
$$

For stationary or homogeneous conditions, NR is approximately unity. We calculate NR for the aircraft and lidar data using the same number of samples and subsamples as Mahrt (1998) $(I=6, J=6$ for 1 -h averaging intervals and $I=6, J=10$ for $34-\mathrm{km}$ averaging intervals).

The NR values often range between 1 and 2 (Fig. 11), which indicates quite stationary and homogeneous conditions according to Mahrt (1998). When using 34-km averaging intervals for the lidar data, NR is generally slightly larger (mean NR is 2.0) than for 1-h averaging intervals (mean NR is 1.4), which means that the conditions become less stationary for longer averaging intervals. The mean NR for the aircraft is 1.7. This indicates that on the average the aircraft data can be considered as homogeneous and that no major

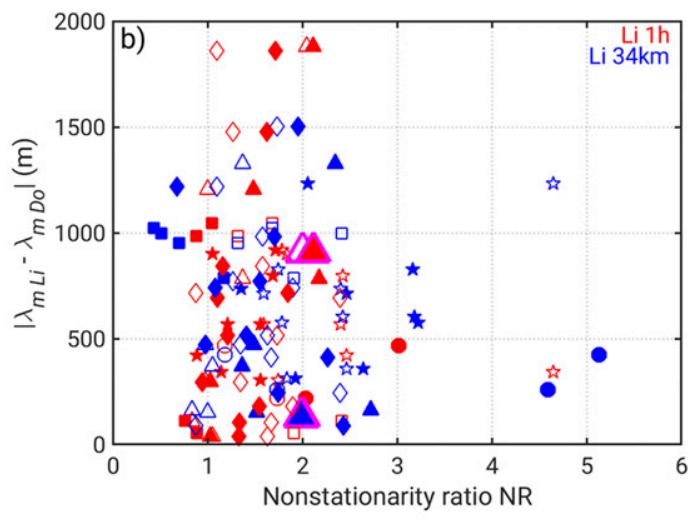

FIG. 11. Relationship between the nonstationarity ratio NR and the difference in (a) integral length scale $l_{w}$, (b) spectral peak wavelength $\lambda_{m}$, and (c) vertical velocity variance $\sigma_{w}^{2}$ between lidar and aircraft measurements. Red markers indicate 1 -h averaging intervals and blue markers $34-\mathrm{km}$ averaging intervals for the lidar data. The nonstationarity ratio NR is calculated for aircraft data (unfilled markers) and lidar data (filled markers). Big triangles with pink edges indicate values for leg B5 (flight B, leg 5; see Table 1 and Fig. 2). NR for leg B5 is very similar for aircraft and lidar data for the 34-km averaging interval, which is why the unfilled marker is not visible. For meaning of markers see Fig. 4.

heterogeneity is induced by surface conditions, which is in agreement with the rather homogeneous land surface conditions in the investigation area (Marsham et al. 2007).

There is no clear relationship between larger values of NR and larger differences between $l_{w}, \lambda_{m}$, and $\sigma_{w}^{2}$ values from lidar and aircraft measurements (Fig. 11). The example of leg B5 nicely illustrates this missing relationship. For leg B5, NR is around 2 for both lidar and aircraft data, which is likely related to the inhomogeneous distribution of convective cells during the averaging intervals (Fig. 8). Despite similar NR values, the differences in $\lambda_{m}$ and $\sigma_{w}^{2}$ values between aircraft and lidar data is much larger for the 1-h averaging intervals $\left(\Delta \lambda_{m 1 \mathrm{~h}}=912 \mathrm{~m}, \Delta \sigma_{w}^{2}=0.28 \mathrm{~m}^{2} \mathrm{~s}^{-2}\right)$ than for the $34-\mathrm{km}$ averaging intervals $\left(\Delta \lambda_{m} 34 \mathrm{~km}=133 \mathrm{~m}\right.$, $\Delta \sigma_{w}^{2}=0.10 \mathrm{~m}^{2} \mathrm{~s}^{-2}$ ) (Figs. 11b,c). This means that nonstationary or heterogeneous conditions cannot be used as an explanation for the large differences in $l_{w}, \lambda_{m}$, and $\sigma_{w}^{2}$ values between aircraft and lidar data.

\section{c. Statistical error of $\sigma_{w}^{2}$}

The statistical error is calculated as the sum of systematic and random error after Lenschow et al. (1994), as described in section $4 \mathrm{c}$ and is shown as the error bars in Fig. 7. For leg B5 and also for most of the other 
samples, it is evident that the differences between $\sigma_{w}^{2}$ values from aircraft and lidar are larger than the uncertainty range given by the statistical error. Also on the average, the absolute difference is 2.5 times larger than the statistical error. Besides, on $\sigma_{w}^{2}$ itself, the statistical error depends on $l_{w}$ and the sample length [Eqs. (8)(10)]. It generally decreases for larger sample lengths keeping $l_{w}$ constant and increases for larger $l_{w}$ when the sample length is the same. For example, doubling $l_{w}$ increases the systematic error by a factor of 2 [Eq. (8)] and the random error by a factor of $\sqrt{2}$ [Eq. (9)]. In section $5 \mathrm{a}$, we found a relative uncertainty of $30 \%$ for $l_{w}$ from lidar measurements, which could increase the random error (which is much larger than the systematic error) by $55 \%$. This means that even an increase of $l_{w}$ by $30 \%$ is not sufficient to enlarge the uncertainty range of the statistical error for lidar measurements $\left[\overline{\epsilon_{\mathrm{stat} L i}}=\right.$ $\left.0.08 \mathrm{~m}^{2} \mathrm{~s}^{-2}\left(0.05 \mathrm{~m}^{2} \mathrm{~s}^{-2}\right)\right]$ to explain the mean absolute difference in $\sigma_{w}^{2}$ between lidar and aircraft data $\left[\overline{\left|\Delta \sigma_{w \mathrm{Li} / \mathrm{Do}}^{2}\right|}=0.17 \mathrm{~m}^{2} \mathrm{~s}^{-2}\left(0.13 \mathrm{~m}^{2} \mathrm{~s}^{-2}\right)\right]$ for 1 -h $(34 \mathrm{~km})$ averaging intervals. Although stationarity and homogeneity are given for many of the samples (section $5 \mathrm{~b}$ and Fig. 11), the corresponding statistical errors are not large enough to encompass the differences in $\sigma_{w}^{2}$ (Fig. 7). These results indicate that even the consideration of all error sources does not sufficiently explain the differences in $\sigma_{w}^{2}$ between lidar and aircraft data.

\section{Summary and conclusions}

In the framework of the CSIP campaign, which was conducted in summer 2005 in southern England, the Dornier 128 research aircraft performed horizontal flight legs in a mostly cloud-free CBL, and a wind lidar was simultaneously operated in vertical stare mode. The 34-km flight legs of the aircraft were approximately parallel to the mean wind and centered over the position of the wind lidar at Chilbolton. Data from three morning and two early-afternoon flights are analyzed. The main aims are to compare CBL characteristics based on temporal (wind lidar) and spatial (aircraft) measurements in order to investigate to what extent they are comparable, as well as to discuss possible reasons for differences. Therefore, we calculate the integral length scale $l_{w}$, the wavelength at the spectral peak $\lambda_{m}$, and the vertical velocity variance $\sigma_{w}^{2}$ from both measurement platforms. To compare spatial and temporal measurements, we convert the temporal lidar measurements to space by using the mean horizontal wind speed along the individual legs. All aircraft parameters are based on the complete 34-km flight leg, while the averaging interval for the lidar is either $1 \mathrm{~h}$ or a longer period that corresponds to the $34-\mathrm{km}$ flight leg (ranging between 1.5 and nearly $5 \mathrm{~h}$ ). The profiles are scaled with the CBL depth $z_{i}$, which we estimate from lidar backscatter data, and $\sigma_{w}^{2}$ is scaled with the convective velocity scale $w_{*}$ from a nearby energy balance station.

The $l_{w}$ values mainly range from 100 to $200 \mathrm{~m}$, and the $\lambda_{m}$ values mostly group between 500 and $2000 \mathrm{~m}$, but the correlation between individual aircraft- and lidarderived values turns out to be poor $\left(R^{2}<0.17\right)$. This is also reflected by small differences in the mean values from lidar and aircraft data compared to larger mean absolute differences. Both parameters show no clear height dependence in the CBL. These results are independent whether $1-\mathrm{h}$ or $34-\mathrm{km}$ averaging intervals are used for the lidar. The $\sigma_{w}^{2}$ values from both aircraft and lidar-independent of the applied averaging intervalfollow the classical textbook profile introduced by Lenschow et al. (1980), although the scatter is considerable. The correlation in $\sigma_{w}^{2}$ between aircraft and lidar data increases from $R^{2}=0.63$ to $R^{2}=0.79$ when 34-km averaging intervals-instead of $1 \mathrm{~h}$-are used for the lidar.

To explain the large differences and the often poor correlations for the turbulence quantities derived from both instruments for individual flight legs, we address three possible reasons: the assumption made for the transfer wind speed, nonstationarity and heterogeneity during the averaging intervals, and the statistical error for $\sigma_{w}^{2}$.

(i) To assess the uncertainty of $l_{w}, \lambda_{m}$, and $\sigma_{w}^{2}$ on the horizontal wind speed value used for the transfer from time to space for the lidar data, we calculate the mean and standard deviation of the horizontal wind speed in the CBL for each flight, use these values as the transfer wind speed, and calculate $l_{w}$, $\lambda_{m}$, and $\sigma_{w}^{2}$ for the new spatial samples. Depending on the used transfer wind speed, the cells in the spatial samples are either stretched or compressed and the overall length of the time series varies for the $34-\mathrm{km}$ averaging intervals. We find a strong dependency of $l_{w}$ and $\lambda_{m}$ from lidar data on the transfer wind speed, while there is nearly no dependency of $\sigma_{w}^{2}$. For individual legs, $l_{w}$ and $\lambda_{m}$ vary by about $30 \%$ on the average within the range of the standard deviation of the transfer wind speed. At least for $l_{w}$, this is large enough to explain the mean differences between aircraft and lidar data (around 25\%).

(ii) We estimate the nonstationarity for the lidar data and heterogeneity for the aircraft data using the NR after Mahrt (1998). On the average, the conditions during the samples can be considered as stationary and homogeneous indicated by NR ranging between 1 and 2, although some individual 
samples clearly show nonstationary and heterogeneous conditions (NR $>2$ ). There is, however, no clear indication that large differences in $l_{w}, \lambda_{m}$, and $\sigma_{w}^{2}$ calculated from lidar and aircraft data are related to large NR.

(iii) We calculate the statistical error for $\sigma_{w}^{2}$ as the sum of systematic and random error after Lenschow et al. (1994) and find that its magnitude is most of the time not large enough to encompass the difference between aircraft and lidar data. On the average, the absolute difference in $\sigma_{w}^{2}$ is 2.5 times larger than the mean statistical error $\left(0.17 \mathrm{~m}^{2} \mathrm{~s}^{-2}\right.$ vs $0.07 \mathrm{~m}^{2} \mathrm{~s}^{-2}$ for 1 -h averaging intervals). The uncertainty arising for $l_{w}$ from the assumption on the transfer wind speed is also not sufficient to enlarge the statistical error.

Overall, we find that the weak correlation between $l_{w}$ and $\lambda_{m}$ from lidar and aircraft data could be related to the ignorance of the true translation of speed of the convective cells, which suggests caution when deducing CBL characteristics from temporal samples that are transferred to space, as the uncertainty is quite large. Our analysis does not allow us to draw any clear conclusions about what causes the differences in $\sigma_{w}^{2}$ between lidar and aircraft data. To retrieve the true translation speed of convective cells, arrays of vertical pointing lidars could be installed (e.g., Maurer et al. 2016) to track convective cells in the mixed layer of the CBL, like it has been done with tower measurements for cells in the surface layer (e.g., Powell and Elderkin 1974). Another possibility to track turbulence elements in space is based on lidars that are installed at elevated locations and scan into the mean wind direction at low elevation angles (e.g., Higgins et al. 2012; Pantillon et al. 2018). By performing synchronized coplanar scans with wind lidars, areawide information on the two-dimensional wind in the plane can be retrieved with the dual-Doppler technique that then allow us to directly obtain information on spatial CBL characteristics (e.g., Träumner et al. 2015).

Acknowledgments. We greatly appreciate the assistance of the many CSIP participants from the United Kingdom and Germany. The British part of the CSIP project was funded by the Natural Environment Research Council (NERC): NER/O/S/2002/00971. We also thank the crew from the Institute of Flight Guidance of Technische Universität Braunschweig, Germany, especially the Do 128 pilots Rolf Hankers and Thomas Feuerle. Finally, we thank two anonymous reviewers for their clear and helpful comments and suggestions.

\section{REFERENCES}

Attié, J.-L., and P. Durand, 2003: Conditional wavelet technique applied to aircraft data measured in the thermal internal boundary layer during sea breeze events. Bound.-Layer Meteor., 106, 359-382, https://doi.org/10.1023/A:1021262406408.

Banta, R. M., and Coauthors, 2013: Observational techniques: Sampling the mountain atmosphere. Mountain Weather Research and Forecasting, F. Chow, S. De Wekker, and B. Snyder, Eds., Springer, 409-530.

Barlow, J. F., T. M. Dunbar, E. G. Nemitz, C. R. Wood, M. W. Gallagher, F. Davies, E. O'Connor, and R. M. Harrison, 2011: Boundary layer dynamics over London, UK, as observed using Doppler lidar during REPARTEE-II. Atmos. Chem. Phys., 11, 2111-2125, https://doi.org/10.5194/acp-11-2111-2011.

Beyrich, F., and J.-P. Leps, 2012: An operational mixing height data set from routine radiosoundings at Lindenberg: Methodology. Meteor. Z., 21, 337-348, https://doi.org/10.1127/ 0941-2948/2012/0333.

Bonin, T. A., W. G. Blumberg, P. M. Klein, and P. B. Chilson, 2015: Thermodynamic and turbulence characteristics of the southern Great Plains nocturnal boundary layer under differing turbulent regimes. Bound.-Layer Meteor., 157, 401-420, https://doi.org/10.1007/s10546-015-0072-2.

- and Coauthors, 2017: Evaluation of turbulence measurement techniques from a single Doppler lidar. Atmos. Meas. Tech., 10, 3021-3039, https://doi.org/10.5194/amt-10-3021-2017.

Browning, K. A., and Coauthors, 2007: The Convective Storm Initiation Project. Bull. Amer. Meteor. Soc., 88, 1939-1955, https://doi.org/10.1175/BAMS-88-12-1939.

Brugger, P., K. Träumner, and C. Jung, 2016: Evaluation of a procedure to correct spatial averaging in turbulence statistics from a Doppler lidar by comparing time series with an ultrasonic anemometer. J. Atmos. Oceanic Technol., 33, 2135-2144, https://doi.org/10.1175/JTECH-D-150136.1.

Caramori, P., P. Schuepp, R. Desjardins, and J. MacPherson, 1994: Structural analysis of airborne flux estimates over a region. J. Climate, 7, 627-640, https://doi.org/10.1175/1520-0442(1994) 007<0627:SAOAFE $>2.0 . \mathrm{CO} ; 2$.

Caughey, S. J., and S. G. Palmer, 1979: Some aspects of turbulence structure through the depth of the convective boundary layer. Quart. J. Roy. Meteor. Soc., 105, 811-827, https://doi.org/ 10.1002/qj.49710544606.

Corsmeier, U., R. Hankers, and A. Wieser, 2001: Airborne turbulence measurements in the lower troposphere onboard the research aircraft Dornier 128-6, D-IBUF. Meteor. Z., 10, 315329, https://doi.org/10.1127/0941-2948/2001/0010-0315.

Desjardins, R. L., J. I. Macpherson, P. H. Schuepp, and F. Karanja, 1989: An evaluation of aircraft flux measurements of $\mathrm{CO}_{2}$, water vapor and sensible heat. Bound.-Layer Meteor., 47, 5569, https://doi.org/10.1007/BF00122322.

Drüe, C., and G. Heinemann, 2002: Turbulence structures over the marginal ice zone under flow parallel to the ice edge: Measurements and parameterizations. Bound.-Layer Meteor., 102, 83-116, https://doi.org/10.1023/A:1012776719250.

Emeis, S., 2011: Surface-Based Remote Sensing of the Atmospheric Boundary Layer. Atmospheric and Oceanographic Sciences Library, Vol. 40, Springer, 174 pp.

Foken, T., R. Leuning, S. R. Oncley, and M. Mauder, 2012: Corrections and data quality control. Eddy Covariance: A Practical Guide to Measurement and Data Analysis, M. Aubinet, T. Vesala, and D. Papale, Eds., Springer, 85-131. 
Frehlich, R., 1997: Effects of wind turbulence on coherent Doppler lidar performance. J. Atmos. Oceanic Technol., 14, 54-75, https://doi.org/10.1175/1520-0426(1997)014<0054: EOWTOC $>2.0 . \mathrm{CO} ; 2$.

_ , and L. Cornman, 2002: Estimating spatial velocity statistics with coherent Doppler lidar. J. Atmos. Oceanic Technol., 19, 355-366, https://doi.org/10.1175/1520-0426-19.3.355.

Fuertes, F. C., G. V. Iungo, and F. Porté-Agel, 2014: 3D turbulence measurements using three synchronous wind lidars: Validation against sonic anemometry. J. Atmos. Oceanic Technol., 31, 1549-1556, https://doi.org/10.1175/JTECH-D13-00206.1.

Grund, C. J., R. M. Banta, J. L. George, J. N. Howell, M. J. Post, R. Richter, and A. M. Weickmann, 2001: High-resolution Doppler lidar for boundary layer and cloud research. J. Atmos. Oceanic Technol., 18,376-393, https://doi.org/10.1175/ 1520-0426(2001)018<0376:HRDLFB > 2.0.CO;2.

Grunwald, J., N. Kalthoff, F. Fiedler, and U. Corsmeier, 1998: Applications of different flight strategies to determine areally averaged turbulent fluxes. Contrib. Atmos. Phys., 71, 83-302.

Hasel, M., C. Kottmeier, U. Corsmeier, and A. Wieser, 2005: Airborne measurements of turbulent trace gas fluxes and analysis of eddy structure in the convective boundary layer over complex terrain. Atmos. Res., 74, 381-402, https://doi.org/ 10.1016/j.atmosres.2004.06.010.

Higgins, C. W., M. Froidevaux, V. Simeonov, N. Vercauteren, C. Barry, and M. B. Parlange, 2012: The effect of scale on the applicability of Taylor's frozen turbulence hypothesis in the atmospheric boundary layer. Bound.-Layer Meteor., 143, 379-391, https://doi.org/10.1007/s10546-012-9701-1.

Kaimal, J. C., and J. J. Finnigan, 1994: Atmospheric Boundary Layer Flows: Their Structure and Measurements. Oxford University Press, $304 \mathrm{pp}$.

— J. C. Wyngaard, D. A. Haugen, O. R. Coté, and Y. Izumi, 1976: Turbulence structure in the convective boundary layer. J. Atmos. Sci., 33, 2152-2169, https://doi.org/10.1175/ 1520-0469(1976)033<2152:TSITCB > 2.0.CO;2.

Kalthoff, N., M. Fiebig-Wittmaack, C. Meißner, M. Kohler, M. Uriarte, I. Bischoff-Gauß, and E. Gonzales, 2006: The energy balance, evapo-transpiration and nocturnal dew deposition of an arid valley in the Andes. J. Arid Environ., 65, 420-443, https:// doi.org/10.1016/j.jaridenv.2005.08.013.

—, and Coauthors, 2013: KITcube-A mobile observation platform for convection studies deployed during HyMeX. Meteor. Z., 22, 633-647, https://doi.org/10.1127/0941-2948/ 2013/0542.

Kelly, R. D., E. A. Smith, and J. I. MacPherson, 1992: A comparison of surface sensible and latent heat fluxes from aircraft and surface measurement in FIFE 1987. J. Geophys. Res., 97, 18 445-18 453, https://doi.org/10.1029/92JD01048.

Kronland-Martinet, R., J. Morlet, and A. Grossmann, 1987: Analysis of sound patterns through wavelet transforms. Int. J. Pattern Recognit. Artif. Intell., 1, 273-302, https://doi.org/10.1142/ S0218001487000205.

Lambert, D., and P. Durand, 1998: Aircraft to aircraft intercomparison during SEMAPHORE. J. Geophys. Res., 103, 25109 25 123, https://doi.org/10.1029/97JC02199.

Lenschow, D. H., 1986: Probing the Atmospheric Boundary Layer. Amer. Meteor. Soc., 269 pp.

, and P. L. Stephens, 1980: The role of thermals in the convective boundary layer. Bound.-Layer Meteor., 19, 509-532, https://doi.org/10.1007/BF00122351.
__ , and L. Kristensen, 1985: Uncorrelated noise in turbulence measurements. J. Atmos. Oceanic Technol., 2, 6882, https://doi.org/10.1175/1520-0426(1985)002<0068: $\mathrm{UNITM}>2.0 . \mathrm{CO} ; 2$.

_- and B. B. Stankov, 1986: Length scales in the convective boundary layer. J. Atmos. Sci., 43, 1198-1209, https://doi.org/ 10.1175/1520-0469(1986)043<1198:LSITCB>2.0.CO;2.

_ J. J. Wyngaard, and W. T. Pennell, 1980: Mean field and second-moment budgets in a baroclinic, convective boundary layer. J. Atmos. Sci., 37, 1313-1326, https://doi.org/10.1175/ 1520-0469(1980)037<1313:MFASMB > 2.0.CO;2.

_, J. Mann, and L. Kristensen, 1994: How long is long enough when measuring fluxes and other turbulence statistics? $J$. Atmos. Oceanic Technol., 11, 661-673, https://doi.org/10.1175/ 1520-0426(1994)011<0661:HLILEW>2.0.CO;2.

Mahrt, L., 1998: Flux sampling errors for aircraft and towers. J. Atmos. Oceanic Technol., 15, 416-429, https://doi.org/ 10.1175/1520-0426(1998)015<0416:FSEFAA > 2.0.CO;2.

Mann, J., and Coauthors, 2009: Comparison of 3D turbulence measurements using three staring wind lidars and a sonic anemometer. Meteor. Z., 18, 135-140, https://doi.org/10.1127/ 0941-2948/2009/0370.

Marsham, J. H., C. J. Morcrette, K. A. Browning, A. M. Blyth, D. J. Parker, U. Corsmeier, N. Kalthoff, and M. Kohler, 2007: Variable cirrus shading during CSIP IOP 5. Part I: Effects on convective initiation. Quart. J. Roy. Meteor. Soc., 133, $1643-$ 1660, https://doi.org/10.1002/qj.124.

Mauder, M., R. L. Desjardins, and I. MacPherson, 2007: Scale analysis of airborne flux measurements over heterogeneous terrain in a boreal ecosystem. J. Geophys. Res., 112, D13112, https://doi.org/10.1029/2006JD008133.

Maurer, V., N. Kalthoff, A. Wieser, M. Kohler, M. Mauder, and L. Gantner, 2016: Observed spatiotemporal variability of boundary-layer turbulence over flat, heterogeneous terrain. Atmos. Chem. Phys., 16, 1377-1400, https://doi.org/10.5194/ acp-16-1377-2016.

Neff, W. D., 1990: Remote sensing of atmospheric processes over complex terrain. Atmospheric Processes over Complex Terrain, Meteor. Monogr., No. 23, Amer. Meteor. Soc., 173-228.

Newman, J. F., T. A. Bonin, P. M. Klein, S. Wharton, and R. K. Newsom, 2016a: Testing and validation of multi-lidar scanning strategies for wind energy applications. Wind Energy, 19, 2239-2254, https://doi.org/10.1002/we.1978.

_, P. M. Klein, S. Wharton, A. Sathe, T. A. Bonin, P. B. Chilson, and A. Muschinski, 2016b: Evaluation of three lidar scanning strategies for turbulence measurements. Atmos. Meas. Tech., 9, 1993-2013, https://doi.org/10.5194/amt-9-1993-2016.

Pantillon, F., A. Wieser, B. Adler, U. Corsmeier, and P. Knippertz, 2018: Overview and first results of the Wind and Storms Experiment (WASTEX): A field campaign to observe the formation of gusts using a Doppler lidar. Adv. Sci. Res., 15, 91-97, https://doi.org/10.5194/asr-15-91-2018.

Pearson, G., F. Davies, and C. Collier, 2010: Remote sensing of the tropical rain forest boundary layer using pulsed Doppler lidar. Atmos. Chem. Phys., 10, 5891-5901, https://doi.org/10.5194/ acp-10-5891-2010.

Powell, D. C., and C. E. Elderkin, 1974: An investigation of the application of Taylor's hypothesis to atmospheric boundary layer turbulence. J. Atmos. Sci., 31, 990-1002, https://doi.org/10.1175/1520-0469(1974)031<0990:AIOTAO> 2.0.CO;2.

Seibert, P., F. Beyrich, S.-E. Gryning, S. Joffre, A. Rasmussen, and P. Tercier, 2000: Review and intercomparison of operational 
methods for the determination of the mixing height. Atmos. Environ., 34, 1001-1027, https://doi.org/10.1016/S1352-2310(99) 00349-0.

Shuttleworth, W. J., 1988: Macrohydrology-The new challenge for process hydrology. J. Hydrol., 100, 31-56, https://doi.org/ 10.1016/0022-1694(88)90180-1.

Stull, R. B., 1988: An Introduction to Boundary Layer Meteorology. Kluwer Academic, 666 pp.

Tonttila, J., E. J. O'Connor, A. Hellsten, A. Hirsikko, C. O’Dowd, H. Järvinen, and P. Räisänen, 2015: Turbulent structure and scaling of the inertial subrange in a stratocumulus-topped boundary layer observed by a Doppler lidar. Atmos. Chem. Phys., 15, 5873-5885, https:// doi.org/10.5194/acp-15-5873-2015.

Torrence, C., and G. P. Compo, 1998: A practical guide to wavelet analysis. Bull. Amer. Meteor. Soc., 79, 61-78, https://doi.org/ 10.1175/1520-0477(1998)079<0061:APGTWA > 2.0.CO;2.

Träumner, K., C. Kottmeier, U. Corsmeier, and A. Wieser, 2011: Convective boundary-layer entrainment: Short review and progress using Doppler lidar. Bound.-Layer Meteor., 141, 369391, https://doi.org/10.1007/s10546-011-9657-6.

_- T. Damian, C. Stawiarski, and A. Wieser, 2015: Turbulent structures and coherence in the atmospheric surface layer. Bound.-Layer Meteor., 154, 1-25, https://doi.org/10.1007/ s10546-014-9967-6.

Treviño, G., and E. Andreas, 1996: On wavelet analysis of nonstationary turbulence. Bound.-Layer Meteor., 81, 271-288, https://doi.org/10.1007/BF02430332.

Web of Science, 2018a: Wind lidar. Web of Science, accessed 17 December 2018, http://apps.webofknowledge.com/.

_ 2018b: Doppler lidar. Web of Science, accessed 17 December 2018, http://apps.webofknowledge.com/.

Wyngaard, J. C., 1973: On surface-layer turbulence. Workshop on Micrometeorology, D. A. Haugen, Ed., Amer. Meteor. Soc., 101-149.

Young, G., 1988: Turbulence structure in the convective boundary layer. Part I: Variability of normalized turbulence statistics. J. Atmos. Sci., 45, 719-726, https://doi.org/10.1175/ 1520-0469(1988)045<0719:TSOTCB > 2.0.CO;2. 